\title{
Azorín, enfermo y escritor, ante la medicina
}

\author{
Azorín, Sick and Writer, before Medicine
}

\author{
Montserrat Escartín Gual \\ Universitat de Girona
}

montserrat.escartin@udg.edu

ORCID iD: http://orcid.org/0000-0002-2449-8355

\section{RESUMEN}

El artículo estudia la relación de Azorín con la enfermedad desde un enfoque distinto al que suele adoptar la crítica, que ha interpretado su presencia en la obra del novelista como metáfora de la crisis de fin de siglo. Nuestro trabajo la examina en términos científicos y reales, al ser la experiencia sufrida por el propio autor, quien proyecta su patología en personajes de ficción, que investigamos, además de exponer las características del mal, su terapéutica e interesarse por todo tipo de bibliografía médica, antigua y de su tiempo. En suma, el artículo revisa la enfermedad y los médicos como una constante en la literatura de Martínez Ruiz, que se traduce en artículos ( «La medicina», «El doctor»), novelas de juventud y madurez (Diario de un enfermo, 1901; El enfermo, 1943) o ensayos (Los médicos, 1966).

Palabras Clave: enfermedad; medicina y literatura; melancolía; novela; Azorín.

\begin{abstract}
The paper studies the relationship of Azorin with medicine from a different approach which often takes the critical who interpreted the presence of the disease in his work as a metaphor for the crisis of the crisis of the end of the century. Our work examines scientific and real terms, as the suffering experienced by the author himself, who projected his pathology to fictional characters, we investigated, in addition to exposing the characteristics of disease and its therapeutic and his interest in all kinds of medical literature, ancient and recent. In summary, the article reviews the illness and doctors as a constant in Martínez Ruiz's literature, resulting in newspaper articles («Medicine», «The Doctor»), youth and maturity novels (Diary of a sick, 1901, The sick, 1943) or essays (Doctors, 1966).
\end{abstract}

Key words: Disease; Medicine and Literature; Melancholy; Novel; Azorín. 
Aunque la relación de Martínez Ruiz con la Medicina fue constante y profunda ${ }^{1}$, son pocos los estudios que tratan del conocimiento e interés del novelista por los diferentes aspectos de esta ciencia, salvo los artículos de los doctores Francisco M. Merenciano (1947) y Luis S. Granjel (1960), sobre enfermos y médicos en las obras del autor. En el primero, se analizan tres personajes de Azorín vistos por un psiquiatra; mientras que el segundo, repasa los médicos y enfermos que aparecen en las obras del alicantino. Completando lo dicho por ambos estudiosos, nuestro trabajo ahondará en la psicología del escritor como enfermo hipocondríaco, cuyo reflejo en su literatura no se reduce solo al retrato de personajes similares; sino al estudio del particular psiquismo del enfermo, es decir, del mismo Martínez Ruiz, de la neurastenia y de su terapéutica.

Podemos rastrear los juicios del autor sobre temas médicos gracias a declaraciones suyas en artículos («El doctor», 1944², «La medicina», 1976)33; comentarios de libros científicos que le interesaron ${ }^{4}$ o, en sus novelas, a través de lecturas ${ }^{5}$ y opiniones de personajes —enfermos afligidos por un mal $^{6}$, médicos (Granjel, 1960: 318) — o del mismo narrador, caso de El enfermo (1943) ${ }^{7}$ y Pueblo (1949), subtitulada «Novela de los que trabajan y sufren». En suma, la obsesión de Martínez Ruiz por la enfermedad y los médicos fue tal que hizo afirmar al Dr. Laín Entralgo: «Cuando se quiera edificar una doctrina completa acerca del hombre enfermo, no será ocioso recurrir a los primores descriptivos de Azorín» (en Granjel, 1960: 317).

Prueba del atractivo que la medicina suscitó en nuestro autor es una obra suya, no muy conocida, titulada Los médicos, donde Martínez Ruiz menciona

1 «Su padrino, don José Martínez, es médico. Su hermano Ramón estudia medicina. El médico de la familia, el Dr. Alfonso; otro médico amigo, don José Pérez Bernabeu» (Granjel, 1960: 54).

2 Vid. Azorín [José Martínez Ruiz]. «El doctor», $A B C .14$ de febrero, 1944.

${ }^{3}$ En Pensando en España, 1864, Azorín afirma: «Creo que la Medicina no es opinión, sino casos. No existe el mal en abstracto. Lo que existe son enfermos... la realidad es lo que me preocupa» (en Granjel, 1960: 325).

${ }^{4}$ Lector empedernido de literatura médica por la aprensión de estar gravemente enfermo, Azorín se interesa por la neurastenia y menciona una colección «en la que figura un volumen — no lo conozco — dedicado a la higiene del neurasténico» (Azorín, 1960: 81-82).

5 El protagonista de El escritor consulta «El libro de los enfermos, por A. F. Ozanam» (Azorín, 1957a: 65-66).

${ }^{6}$ En Salvadora de Olbena, dos personajes hablan sobre el organismo humano y su salud: «-Nuestro cuerpo es un laboratorio de química. He oído decir al Dr. Casal que en el s. XVII creían que el hígado no sirve para nada. — ¡Ahí tiene usted el gran químico!» (Azorín, 1944: 114).

${ }^{7}$ «...la profesión médica, la más difícil de todas, encierra un drama apasionante $[\ldots]$ no es el de la incurabilidad del enfermo, sino el más angustioso, si cabe, de los límites de la ciencia» (Azorín, 2006: 139). 
a profesionales — reales ${ }^{8}$ o imaginarios ${ }^{9}$, modernos o de otras épocas — ${ }^{10}$, que aparecen en sus obras; enfermos cuyas dolencias físicas o espirituales son el nudo de una leve trama argumental; conocimientos médicos del momento ${ }^{11} \mathrm{o}$ de siglos anteriores ${ }^{12}$; reseñas de libros científicos recién publicados u obras de ficción escritas por profesionales de la salud, caso de Georges Duhamel, novelista y cirujano en la Gran Guerra, a quien le dedica un elogioso capítulo al publicar Diario de un Aspirante a Santo, destacando su habilidad para describir estados de ánimo y enfermedades del alma. Algo parecido propone el alicantino en su novela Tomás Rueda hablando de la importancia que adquieren en su protagonista "itantos matices e incidentes que le han llegado a lo hondo del espíritu!» (Azorín, 1941: 24); o, en El escritor (1942), del parecido entre los estados místicos y los de creatividad literaria, porque ambos tienen expresión somática similar, vivida como una enfermedad.

Martínez Ruiz es buen conocedor de obras de arte que representan temas médicos — como La lección de anatomía de Rembrandt: «El cuadro es un

${ }^{8}$ Muchos conocidos del autor practicaron esta profesión —además del novelista Pío Baroja - «los estudiantes de Medicina don Francisco Villalta y don Francisco Bonmatí» y su médico de cabecera «-Antonio Alfonso Prats - y otros dos médicos — don Miguel Mas y don José Payá Bernabé-》 (Alfonso, 1958: 31). «En tales amistades, a las que reforzaba una identidad de convicciones políticas, nació la simpatía del escritor por los médicos y su quehacer» (Granjel, 1958: 30); «Destaca su amistad con el Dr. G.Marañón, en intimidad casi familiar. Azorín conoció a Cajal, Teófilo Hernando, Jiménez Díaz, Pittaluga, Izquierdo, Vega-Díaz, De la Peña, y tantos otros que le demostraron su amistad y cariño» (Granjel, 1960: 55). Muchos aparecen en sus novelas: «los médicos que asisten al protagonista en sus varias dolencias son reencarnaciones de ilustres galenos amigos todos de Azorín» (Granjel, 1958: 169); Gregorio Marañón y Teófilo Hernando se reconocen en los personajes de García de Rodas e Irala, según los críticos (Vidal, 2007: 230). Vid. Granjel (1960 y 1998).

9 «Víctor Albert tiene dos devociones en Medicina: García de Rodas y Facundo Irala [...] Para mí, García de Rodas y Facundo Irala son dos genios de la Medicina; les tengo profundo cariño. [...] Son escritor y doctor amigos antiguos. [...] Víctor tiene una auténtica amistad con sus médicos. Les quiere y le quieren» (Azorín, 2006: 123, 163, 116 y 118).

${ }^{10}$ En Salvadora de Olbena, se lee: «En Londres se había apasionado de un médico inglés antiguo: Thomas Young. Nació Young en 1773 y murió en 1829 [...] descolló en la botánica, en la óptica y en la medicina...» (Azorín, 1944: 44); en El enfermo, se dedica el capítulo XIV al Dr. Richard Bright (1789-1858): «En los manuales de patología se limitan a consignar que R. Bright ha dado su nombre a la nefritis crónica; pero en los tratados especiales $[\ldots]$ se habla más extensamente y con más precisión de nefritis crónica parenquimatosa» y, el XV, a George Miller Beard que «Fue médico en New York e inventó el nombre de neurastenia» (Azorín, 2006: 108-109 y 113).

${ }^{11}$ «La Asociación francesa ha establecido que el selenio no tiene ninguna acción específica sobre el cáncer. Se puede, sí, con sus sales matar al enfermo, puesto que son extremadamente tóxicas; pero no es posible detener la marcha invasora del cáncer; antes bien, habría que ver si no la favorece» (Azorín, 1966: 54).

12 «Suelo yo hojear los libros antiguos de patología y de terapéutica» (Azorín, 2006: 162). 
gran cuadro, y la ciencia anatómica, madre de la Cirugía, está allí soberbiamente enaltecida» (Azorín, 1966: 22) —; lector de piezas literarias que eligen esta materia ${ }^{13}$; de tratados antiguos de medicina ${ }^{14}$; o publicaciones de médi$\cos$ modernos $^{15}$; y sorprende con escritos sobre distintas medicinas alternativas, caso de la macrobiótica de Huffeland ${ }^{16}$, en su ensayo Los médicos ${ }^{17}$, también mencionada como referente por el protagonista de su novela $E l$ enfermo:

— Todo hombre se estudia, si es inteligente. Tengo yo mi macrobiótica, como la puede tener cualquiera. Los libros de macrobiótica, en realidad, no nos dicen nada; conozco los que se han publicado antiguamente y en los tiempos modernos.

- Sin embargo, existe en ellos, por lo menos en Huffeland, un acerbo de experiencia (Azorín, 2006: 187).

13 Tras evocar la sátira de Molière (El enfermo imaginario) contra los médicos que esclavizan a sus pacientes con «una muchedumbre de drogas, aguas, caldos, píldoras, sellos, pomadas, baños», el alicantino sentencia: «No será buen médico — suponemos nosotros[...] quien, no atendiendo a las grandes causas, imagine un plan complicadísimo, molesto, absurdo, para combatir en cada hora del día los pequeños efectos» (Azorín, 1966: 64-65). En Un pueblecito: Riofrío de Ávila, Martínez Ruiz vuelve a mencionar la misma «obra triste y melancólica de aquel gran artista»: Molière (Azorín, 1976b: 147); en Abogados y médicos, describe cómo pintan Tirso de Molina y Quevedo a estos profesionales; y, en Los médicos, sentencia: «Molière era un adversario decidido de la medicina» [...] En el Don Juan es donde Molière nos ofrece la expresión más concisa y directa de su hostilidad» (Azorín, 1966: 62). Vid. Azorín (1924).

${ }^{14}$ Martínez Ruiz cita a Huarte de San Juan (1575): «cada hombre que enfermase se ha de curar conforme a su particular proporción» (Azorín, 1966: 24). Así, «Las incursiones que hace Azorín en el pasado de la Medicina nacen de su deseo por descubrir cómo entendían los médicos de otras épocas la enfermedad, cuál sería su manera de obrar ante el enfermo» (Granjel, 1960: 323), igual que su personaje: «¿Qué es lo que haría un médico del siglo dieciséis a la cabecera de un enfermo grave? [...] ¿Y la sensación del enfermo sería la misma? ¿Y se retiraría de la casa del mismo modo? ¿Y pensaría, a sus solas, en el enfermo de la misma manera?» (Azorín, 2006: 163).

15 En Andando y pensando, Martínez Ruiz reconoce: «Hace poco leía yo —en un folleto del doctor Marañón - unas palabras de Cajal...» (Azorín, 1959b: 55); «El doctor Gregorio Marañón ha publicado un opúsculo titulado Biología y feminismo. ¿Nos permitirá el doctor Marañón que hagamos algunas observaciones a propósito de su trabajo?» (Azorín, 1959b: 38).

${ }^{16}$ Ch.W.F. Huffeland (1762-1836), médico del rey de Prusia, inventó la voz macrobiótica.

${ }_{17}$ Makrobiotik die oder Kunst, das Leben zu menschliche verlängern. Leipizg, Reclam, 1796. «Macrobióticas o artes de larga vida existen muchas; la de Huffeland, traducida al castellano en 1839 es la más conocida. [...] Entre los excesos que Huffeland nos recomienda que evitemos, incluye la fatiga del cerebro y la violencia del corazón; el cerebro se fatiga con trabajo intenso y continuado; el corazón se violenta con emociones convulsivas» (Azorín, 1966: 25). 
En un capítulo de Los médicos, titulado Sydenham ${ }^{18}$, Azorín habla de este químico y farmacólogo y de sus frascos de láudano ${ }^{19}$. Nuestro autor conoce bien el protagonismo que dicha droga tuvo en manos de algunos escritores, que acabaron creando una dependencia adictiva ${ }^{20}$, tras haberla conocido en el proceso de una enfermedad e ingerirla como paliativo al dolor (phármakon significa a la vez 'remedio y veneno'). Coleridge recurrió al opio buscando un analgésico para sus dolores reumáticos agudos (Escohotado, 2001: 571), mientras que Poe, al láudano y al alcohol para escapar de su angustia: «Cuando estoy solo me abruman los terribles sufrimientos, la degradación y el infortunio que me ha causado el láudano» (en Jamison, 1998: 49).

Si los poetas de la Antigüedad imploraban a Apolo y a las Musas para que les inspirasen versos, los románticos intentaron conseguirlos a través de alcohol y narcóticos. Este es un aspecto de obligada consideración al estudiar la relación medicina-literatura: los estimulantes que han consumido muchos autores para provocarse estados alterados de conciencia y escribir más o mejor: Walter Scott, Mary Shelley, Goethe, Byron, Wordsworth o Keats lo consiguieron gracias al láudano (Escartín, 2014: 5). También Martínez Ruiz demuestra tener noticia de sus efectos al describir la melancolía de un «enfermo» en la ficción:

La mirada de Albert se posa ahora en la receta de láudano opiado o nepentes. Nepentes es hierba que mezclada con vino quita la melancolía. Quisiera muchas veces Víctor disponer de nepentes. [...] En la receta del láudano opiado se pone esta advertencia: "Adviértase que los narcóticos no deben prescribirse cuando el cuerpo está lleno de humores» (Azorín, 2006: 126).

El alicantino tampoco ignora los beneficios de la opoterapia ${ }^{21}$, ni la sueroterapia - que «representa en la Medicina moderna una de las más trascendentales y fecundas conquistas» (Azorín, 1966: 54)—22; expresando un especial

18 Gracias a Thomas Sydenham (1624-1684), las dolencias se individualizan: «Es necesario que el que escribe la historia de las enfermedades observe con atención los fenómenos claros y naturales de las enfermedades, por poco interesantes que parezcan» (Sendrail, 1983: 361-362).

19 «El nombre de Sydenham ha llegado hasta nosotros por el láudano que lleva su apellido y por el análisis que, en 1885, con motivo del cólera, hizo del láudano Sydenham Gabriel de la Puerta» (Azorín, 1966: 18).

${ }^{20}$ El consumo de la morfina, hachís y otras drogas — heroína, láudano, opio o cocaínase convirtió en habitual entre literatos y artistas románticos (Haining, 1975 y Escartín, 2014: $5-6)$.

21 opoterapia 'Procedimiento curativo por el empleo de órganos animales crudos, de sus extractos o de las hormonas aisladas de las glándulas endocrinas' (DRAE).

22 «A España debe la Medicina la sueroterapia [...] Mucho antes que Behringy y Kitasato descubrieran en 1890 este procedimiento, lo había hallado Ferrán» en 1884 (Azorín, 1966: 54). 
interés por la fitoterapia, de cuyos conocimientos da muestras en diversas novelas, como María Fontán (1943):

... [en la tienda] no escaseaban, naturalmente, ni el consabido romero, ni el no menos renombrado tomillo, ni el espliego, alhucema o lavándula ${ }^{23}$, ni la salvia. Había manzanilla fina, romana y común ${ }^{24}$. No se daba por manzanilla, como otros herbolarios, la Matricaria parthenium ${ }^{25}$. No faltaban el árnica ${ }^{26}$, que antes se usaba en las contusiones, ahora inusitada, pero siempre eficaz; ni la parietaria ${ }^{27}$, amiga, claro es, de las paredes, las paredes salitrosas especialmente; ni la blanda malva emoliente ${ }^{28}$ (Azorín, 1963: 26-26).

En Capricho (1943) leemos: «Ante su mirada tiene el poeta un bloque de cristal de roca, y junto a él una cajita de marfil con unas píldoras de convallamarina, convallaria maialis. Ninguna droga más adecuada al feble corazón del poeta que esta en que se halla extractado el lirio de los valles» ${ }^{29}$ (Azorín, 1943b:

23 «Hay un refrán que dice: "Espliego y alhucema son una cosa mesma". Pero, en realidad, el área lingüística de alhucema viene a coincidir con la de la Lavandula latifolia, y la del espliego, con la de la Lavandula spica» (Font, 1980: 656).

24 «El nombre de manzanilla romana (Anthemis nobilis) arranca por lo menos del XVI; en Roma debió cultivarse desde aquel siglo [...] La manzanilla común, que es la que le dio a la romana el nombre genérico de manzanilla, se conocía desde mucho antes» (Font, 1980: 802).

25 A la Matricaria se la denomina Chrysanthemun parthenium: «Parthenion es el nombre que le dieron a esta planta los padres de la Botánica: Teofrastro, Galeno, Dioscórides, etc., derivado de parthenos, muchacha en estado de merecer o virgen, porque, ya desde remotos tiempos, esta especie se emplea para socorrer a las mujeres jóvenes que necesitan regularizar sus menstruos» (Font, 1980: 811).

${ }^{26}$ A la Arnica montana «Se [la] llamaba tabaco de montaña porque los pastores fumaban las flores y las hojas a guisa de tabaco. [...] gozó de fama poco común entre los médicos, lo mismo que entre las gentes del pueblo [...] perdura con todo su honor en muchas farmacopeas [...] desconocida de los grandes farmacólogos de la Antigüedad» (Font, 1980: 826 y 828$)$.

${ }^{27}$ Parietaria officinalis o «parietaria, hierba del muro, albahaquilla de muro [...] Se cría en los muros y en las peñas, en cuyas fisuras o grietas arraiga, y, naturalmente, al pie de los mismos, en los ribazos. [...] Desde el XVIII se dice que "abunda en sal nitrosa y sulfúrea". [...] Con el nombre de helxine, Dioscórides se refiere a esta especie [...]: "La helxine se llama también parietaria y muralis herba"» (Font, 1980: 135-136).

${ }^{28}$ Malva silvestres, «Las malvas se utilizan principalmente en forma de cataplasmas, como emolientes, esto es, para ablandar toda suerte de diviesos y furúnculos» (Font, 1980: 404).

${ }^{29}$ La Convallaria majalis, perteneciente a la familia Ruscaceae, está indicada contra la insuficiencia cardíaca y palpitaciones. Se la conoce como: convalaria, lágrimas de Salomón, lirio convalio, lirio de los valles, lirio de Nuestra Señora, lirio salvaje, muguet, muguete, mugueto... «Las hojas secas se utilizan como medicamento y materia prima para el aislmiento de glucósidos con destino a la preparación de preparados cardíacos, [...] que tienen un efecto muy pronunciado sobre el músculo cardíaco» (Stary, 1990: 72). 
111-112); también, en El enfermo (1943): «Con las atochas ${ }^{30}$ alteran los tomillos y los romeros» (Azorín, 2006: 91); o, en Pueblo (1949), donde el novelista menciona «La manzanilla, la tila, la malva, el cantueso» ${ }^{31}$, dedicando un capítulo al romero: «Romero y niebla». Tras definir el Rosmarinus officinalis como «la planta de los pobres; la planta del pueblo» (Azorín, 1957b: 36 y 39), Martínez Ruiz explica sus virtudes, modo de aplicación — vino de romero, aceite, agua y miel, pues «La miel de romero es la más preciada» (Azorín, 2006: 92) — incluyendo diversas indicaciones médicas:

Los brotes de romero comidos por la mañana con pan y sal fortifican el cerebro; los polvos hechos con las hojas secas impiden la melancolía y alegran el corazón; las hojas majadas curan las llagas frescas; el sahumerio del romero evita la pestilencia; bañarse en agua de romero es rejuvenecerse y cobrar lozanía; mascar el romero quita la sed a los sedientos que van por el monte; el romero cocido en vinagre corrobora los dientes y afirma las muelas que se mueven; la apetencia en los desganados viene con el comer por la mañana dos o tres sopas en vino cocido con romero; la miel del romero es la mejor para letuarios ${ }^{32}$, medicinas y confituras (Azorín, 1957b: 39).

No es necesario buscar en los ensayos de Azorín sus conocimientos sobre botánica - en Lecturas españolas, nuestro autor nombra plantas de modo coloquial: «Amo todos los hierbajos de la montaña: el romero, la mejorana, la salvia, el cantueso» (Azorín, 1962a: 143) — ya que es en novelas, como María Fontán, donde efectúa distinciones de erudito: "Yo he leído que el tomillo es caliente y seco en el tercer grado. ¿Qué es eso de tercer grado? [...] Y lo de que el romero es caliente y seco en el segundo grado ${ }^{33}$ —Pues tampoco lo sé - contestaba sonriendo don Ismael- Esas son cosas del siglo XVIII» (Azorín, 1963: 26-27). Sea como sea, la razón del amor por las hierbas silvestres que siente Martínez Ruiz la explicita él mismo: «Me traen una impresión que no me proporcionan las flores y plantas de los jardines; una impresión de soledad,

30 atocha 'esparto. Planta de la familia de las Gramíneas' (DRAE).

31 cantueso 'Planta perenne, de la familia de las labiadas, semejante al espliego, de 50 a 60 centímetros de altura, con tallos derechos y ramosos, hojas oblongas, estrechas y vellosas, y flores olorosas y moradas, en espiga que remata en un penacho' (DRAE).

32 letuario 'Especie de mermelada' (DRAE).

33 Un autor del XVIII, Juan de Vidós y Miró, afirma: «El romero es caliente, y seco en tercer grado, cura el mal déla cabeça, por causa fría, el estupor, el vértigo,...», cap. IV del Tratado IV: De algunas yerbas, sus virtudes medicinales y complexiones, en Medicina y cirugía racional y espagírica, Zaragoza, 1721. «Andrés de Laguna hace los siguientes comentarios: "Es el romero caliente y seco en el segundo grado. Su sahumerio sirve admirablemente a la tos, al catarro y al romadizo [...] conforta el celebro, el corazón y el estómago; aviva el entendimiento, restituye la memoria perdida, despierta el sentido, y, en suma, es saludable remedio contra todas las enfermedades frías de cabeza y de estómago"» (Font, 1980: 653). 
de libertad, de fortaleza, y de sinceridad» (Azorín, 1962a: 143), no en vano se declara — como el protagonista de El enfermo - «naturalista de afición» (Azorín, 2006: 171).

Aunque, en Los médicos, el autor se acerca al mundo de estos profesionales y sus publicaciones desde un enfoque científico, no rehúye hacer interpretaciones muy personales sobre el poder de la herencia biológica o de los milagros que vencen la enfermedad. A estos les dedica un capítulo donde expone el caso de una Virgencita «que tiene fama de hacer milagros» y por cuya «intercesión han logrado la salud muchos enfermos [...] que estaban desahuciados, abandonados por todos». Su fe emociona al novelista: «¿Habrá en el mundo un espectáculo que inspire más respeto [...] que este del pobre enfermo que con sus familiares va a pedir a la Virgencita que le salve la vida?» (Azorín, 1966: 124 y 126). Aún en relación a las curaciones inexplicables, Martínez Ruiz comenta un libro del momento que examina el problema de los casos obrados por la Virgen de Lourdes, a través del supuesto diálogo entre un médico creyente y otro incrédulo (Lourdes et le Miracle, de René Biot) antes de concluir que hay curaciones difíciles de justificar (Azorín, 1966: 127), igual que hiciera su maestro Montaigne, quien ya había tratado estos supuestos prodigios en el siglo $\mathrm{XVI}^{34}$ :

Y eso es todo, lector; desde los tiempos del alcalde de Burdeos no hemos adelantado nada. Ante el hecho insólito, ante el hecho milagroso, invocamos el poder de la naturaleza. [...] no digamos nunca a nadie que no se puede curar; no sabemos, con certeza, si es incurable; no lo sabe nadie; la Naturaleza tiene sus misterios ignorados de todos (Azorín, 1966: 129 y 164-165).

\section{ENFERMEDADES FÍSICAS Y DOLOR EMOCIONAL}

El interés de Martínez Ruiz por la medicina también se evidencia en escritos a propósito de dolencias modernas ${ }^{35}$ —en especial la sífilis ${ }^{36}$ y la tuberculosis - , mostrando su sensibilidad por «la lucha contra las enfermedades venéreas» (Azorín, 1966: 67). El alicantino pone el ejemplo de países que han hecho aportaciones a la ciencia de la salud, como Alemania y Francia, esta última

${ }^{34}$ Montaigne habla de milagros en el capítulo XXI de sus Ensayos, I, titulado «De la fuerza de la imaginación» y en el XXIII, I, «De la costumbre y de cómo no se cambia fácilmente una ley recibida», donde afirma: «Dependen los milagros de la ignorancia en que estemos de la Naturaleza y no del ser de la Naturaleza» (Montaigne, 2005: 152). 2000).

35 Incluso publica libros sobre temas médicos tratados por el cine (vid. Azorín, 1995 y

${ }^{36}$ Llamada «mal venéreo, gorra, bubas, paturra, pasión torpe saturnina, mal serpentino, pudendagra»y, por su punto de aparición, «mal francés, mal gálico, mal español o mal castellano» (Arana, 1995: 101). 
organizando Juntas ${ }^{37}$ para divulgar información sobre dichos procesos infecciosos y mostrar la dimensión del problema — «La tuberculosis y la sífilis son los dos grandes azotes, a la hora presente, de la humanidad. La sífilis siega anualmente en Francia 140.000 vidas» (Azorín, 1966: 69) — mientras que él, por su parte, hace una valoración de cómo afecta la enfermedad a nuestro país, sea en Andalucía o en Levante ${ }^{38}$. A imitación de Francia, Azorín da noticia de la campaña de propaganda sanitaria que inicia en España el Dr. Navarro Fernández quien, con actitud realista ante nuestra situación, propone diversas medidas para lograr mejoras ${ }^{39}$.

No es extraño que Azorín se interesase por la tuberculosis ${ }^{40}$. Dos estudiosos de esta enfermedad — Cortejoso (1943, 1955, 1956 y 1969) y Sontag (1996) evidencian que la tisis ha sido una de las dolencias más literaturizadas y causante de vocaciones literarias en autores que la sufrieron y, en cuyo decurso o gracias a él, pudieron descubrir su interés por las letras: caso de Musset, Bécquer, Chopin, Novalis, Chéjov, Maragall, Verdaguer, Thoreau, Kafka, Alberti o Cela. La novela del siglo XIX, en especial, está llena de tísicos y descripciones de los síntomas preliminares del mal, ignorando la agonía última y convirtiendo la tuberculosis en el prototipo de una muerte pasiva o de una especie de suicidio $^{41}$. Azorín no fue insensible al nuevo tipo de belleza que había aparecido - fundado en los signos de la enfermedad-, como la morbidez del rostro, la piel blanquecina, el aspecto demacrado que daba una expresión distinguida. Al modo de los retratos románticos - donde la palidez y la naturaleza enfermiza se describían como rasgos de hermosura - en Diario de un enfermo (1901), Martínez Ruiz presenta el prototipo de la amada tuberculosa capaz de enamorar y atraer a un hombre pese a su condición de enferma o debido a ella:

${ }^{37} \mathrm{Su}$ presidente honorario es: «El gran filósofo Bergson. “¡Bergson, presidiendo un comité de propaganda antivenérea!" Exclamarán sorprendidos los indiferentes» (Azorín, 1966: 69).

${ }^{38}$ En Los pueblos, se lee: «Casi todos los enfermos que acabamos de ver, señor Azorín, son tuberculosos; este es el mal de Andalucía. No se come; la falta de nutrición trae la anemia: la anemia acarrea la tisis. En Madrid la mortalidad es del 34 por ciento; en Sevilla rebasa esta cifra; en este pueblo donde yo ejerzo, en Lebrija, pasa del 40 por 100. [...] Y en estos pueblos [levantinos] yo oigo lamentarse también todos los días a los compañeros de usted, de los estragos que la tuberculosis hace entre los labriegos» (Azorín, 1943a: $397-$ 398).

39 Como «la disminución de las causas pre-natales de mortalidad infantil», que «afectan a la mujer en su embarazo. Son la fatiga, la deficiente alimentación, las enfermedades venéreas, la falta de cuidadosa asistencia» (Azorín, 1966: 74).

${ }^{40}$ A la tisis se dedica el capítulo «Deprecación del dolor» en Los médicos (Azorín, 1966: 163-165).

${ }^{41}$ «El desesperado, con frecuencia, no se libera brutalmente de la vida; se priva de todo, se deja ir hasta que cae enfermo de tuberculosis y muere. Y los poetas amaron de manera especial a estos seres, descubriendo en su debilidad fisiológica el signo de una excepcional cualidad espiritual» (Sendrail, 1983: 367). 
Me siento inferior a esta ideal y suprema mujer. La adoro, la amo apasionadamente como a un hermoso sueño que se desvanece; y la quiero más a medida que más se desvanece... Sí, se va sonriente, piadosa, tranquila, augusta; se va silenciosamente, como un postrero rayo de sol, como una lámpara que se apaga, como una flor que cae (Martínez Ruiz, 2015: 297).

En Los pueblos (1905), el autor señala el origen de dicha estética: «¿cómo podréis negar la íntima relación que existe entre el romanticismo y la tez pálida, las ojeras, la delgadez y la infinita desesperanza trágica?» (Azorín, 1943a: 367). Si la salud frágil es considerada un rasgo elegante y un mecanismo que permite evadirse de la realidad y del presente, no extraña que se haya asociado la tisis al ideal de los creadores porque «Aísla, liberándolos de toda preocupación material, de todo nexo con la historia, de toda responsabilidad familiar y social» (Sendrail, 1983: 368).

En paralelo al interés por estas dolencias físicas, Martínez Ruiz muestra su interés por la enfermedad y el dolor, cuya concepción variará a lo largo de los años. En Charivari (1897), el autor estudia el malestar emocional, favorecido por la inteligencia, y confiesa haber leído La douleur universelle, de Sébastian Fraure (1858-1942), uno de los teóricos del anarquismo francés que sitúa la causa del dolor en la estructura social ${ }^{42}$ y no en la Naturaleza.

$\mathrm{Si}$, en Diario de un enfermo (1901), el protagonista se rebela ante la tuberculosis de la esposa por ser un mal sin cura, a partir de La voluntad (1902), y bajo la influencia de Schopenhauer, Martínez Ruiz acepta resignadamente el sufrimiento como un estado de carencia sin carga negativa: «El dolor será siempre inseparable del hombre [...] Sí, el dolor es eterno... y el hombre luchará en vano por destruirlo... El dolor es bello; él da al hombre el más intenso estado de consciencia; él hace meditar; él nos saca de la perdurable frivolidad mundana...» (Azorín, 1943a: 131).

Aunque en obras posteriores la enfermedad siga estando presente, el novelista no abandonará ya esta actitud, ni cuando deba alejarse de su país durante la guerra acusando: «un dolor que será más agudo cuanto más intenso sea el amor que siente por su patria: "Si se pudiera solidificar el fluido nervioso de los que han sufrido y sufren, formaría ese fluido una masa inmensa que podría llenar los infinitos espacios sidéreos"» (Azorín, en Manso, 1993: 177). En su madurez, las afecciones físicas y emocionales que padeció el alicantino le empujaron a seguir analizando la enfermedad dentro de sus novelas ${ }^{43} \mathrm{y}$, en la ancianidad, a identificar la vejez con una dolencia más.

\footnotetext{
42 «...he leído yo La doleur universelle, de Sebastián Fraure, esa obra portentosa de filosofía en que el autor ha llegado a la profundidad de Proudhon y a la elocuencia de Renán. [...] todos sufrimos en este organismo social» (Azorín, 1959a: 279).

${ }^{43}$ En Pueblo se afirma: "Y sentir la limitación, es el dolor; el dolor que no puede desaparecer de la especie humana. Cuanto más aguda, más fina sea la inteligencia, más
} 
Desde su particular visión, Martínez Ruiz nos advierte que en cualquiera de nosotros habita un enfermo. Leemos en Capricho (1943): «Todos lo estamos, unos, mucho, y otros, poco. Si no lo estamos declaradamente, nos hallamos abocados a estarlo. La salud es un estado anormal y provisional» (Azorín, 1943b: 112), pues el hombre que vive en un mundo sin valores, sin valores él mismo, es un hombre enfermo. De hecho, el protagonista de la novela así titulada — El enfermo (1943) — plantea la posibilidad de que el artista sea alguien en la frontera entre la salud y la enfermedad (Sánchez Martín, 1997: 325-326); porque, «si en Arte no se desvaría, como han desvariado tantos y tantos autores de obras geniales, ¿qué es lo que podemos hacer en Arte? Haremos la vulgaridad que todos hacen» (Azorín, 2006: 129).

A pesar de su obsesión por las dolencias, Martínez Ruiz no sintió dolor físico; de haberlo sufrido no habría escrito, como asegura un novelista que sí tuvo la experiencia: "Cuando le llega el momento de sufrir, Daudet ${ }^{44}$ descubre $^{2}$ que el dolor, como la pasión, deja a un lado el lenguaje. Las palabras llegan cuando todo ha acabado ya, se ha calmado ya» (Barnes, en Daudet, 2003: 9-10). Esclavo de drogas para paliar su enfermedad, «a principios de la década de 1880 se hizo más y más patente el hecho de que Daudet padecía una forma de neurosífilis conocida como tabes dorsal (literalmente 'consunción de la espalda')» ${ }^{45}$. Lo que sí compartió Azorín con el autor francés y con Baroja (vid. Baroja, 1896; Fernández Martínez, 2000 y Mandado Gutiérrez, 2007) fue escribir sobre el dolor como respuesta. La diferencia entre ellos es que Daudet lo hizo en un cuaderno de notas ${ }^{46}$ y Martínez Ruiz, en sus novelas.

disociadora será; más sentirá el dolor de vivir; más experimentará la ineluctabilidad de la vida» (Azorín, 1957b: 152).

${ }_{44}$ «Si [Alphonse] Daudet se sentó a la mesa de las más célebres plumas de la época, fue también miembro de un club decimonónico francés harto menos envidiable: el de los escritores sifilíticos [...] Los Tres Grandes fueron Baudelaire, Flaubert y Maupassant. Daudet es quizá el cuarto, puesto que compartiría con Jules de Goncourt» (Barnes, en Daudet, 2003: 97).

45 «...paraliza el sistema nervioso: paresia general y tabes dorsal, normalmente conocida como tabes. [...] empezaba a manifestarse de 15 a 35 años después de la infección inicial» (Barnes, en Daudet, 2003: 12 y 97). Azorín menciona la tabes dorsal en su novela El enfermo, al nombrar a su descubridor: «Little, que dio su nombre a la tabes dorsal espasmódica» (Azorín, 2006: 131).

46 «"El cuaderno justificará una forma fragmentada, que me autorizará a hablar de todo sin necesidad de nexos". [...] Lo que acabaría publicándose como La doulou, forma provenzal de La douleur, en 1930 consta de unas 50 páginas de notas sobre los sufrimientos que hubo de padecer, sobre sus miedos y reflexiones, y sobre la extraña vida social de los pacientes en termas y balnearios» (Barnes, en Daudet, 2003: 16). Azorín también escribe sobre los balnearios. Vid. nota 65 . 


\section{LA MELANCOLÍA DE AZORÍN}

La enfermedad que más preocupa al autor es la hipocondría, por convivir con ella toda su vida, como evidencia un libro de juventud - Charivari (1897)—, donde ya reconoce que este es el mal que le aqueja: «...Me cuesta cada vez más trabajo manejar la pluma (mi neurastenia se acentúa cada día más)» (Azorín, 1959a: 265); razón de que la estudie en sus novelas, desde la primera:

Azorín lleva los médicos a sus obras. Son muchos los que conoce y trata. Toca la Medicina en sus novelas autobiográficas, en momentos de depresión y enfermedad. [...] Azorín se retrata en el Diario de un enfermo y abre de par en par las ventanas de su espíritu atormentado, triste, depresivo (Granjel, 1960: 50 y 54).

Uno de sus síntomas es que los enfermos viven entre dudas e interrogantes preguntándose algo con insistencia y dejando sin responder sus preocupaciones: "¿Qué fin tiene la vida? ¿Qué hacemos aquí abajo? ¿Para qué vivimos? No lo sé; esto es imbécil, abrumadoramente imbécil. Hoy siento más que nunca la eterna y anonadante tristeza de vivir» (Martínez Ruiz, 2015: 247). Así se interroga el protagonista de Diario de un enfermo (1901), aquejado de ennui; mal que llena de hipocondríacos la literatura a finales del siglo XIX:

Durante este período, una tendencia especial, el mal du siècle, se apodera de la juventud. Este exacerba la sensibilidad y empuja al hombre al hastío de lo real, al aburrimiento, al spleen. [...] Esta melancolía, este desencanto se expresa en las obras literarias, y en la creación artística sólo se concibe como nacida del sufrimiento (Sendrail, 1983: 366).

Martínez Ruiz fue uno de tantos escritores afectados por la abulia de fines del XIX, heredera de la antigua melancolía o atrabiliarismo (de atrabilis o bilis negra, fría y seca, 'dolencia producida por humores sombríos y presagios funestos') (Arana, 1995: 121) ${ }^{47}$. Esta enfermedad no solo condiciona la creación de un $\operatorname{artista}^{48}$, sino que acaba empujando a quien la sufre a tratarla como tema;

47 «Los medios de observación, en cuanto a la Medicina - microscopio, radiografía etc.- han ensanchado el campo a la patología. Decididamente hay enfermedades nuevas... que son viejas. Una melancolía, en el siglo XVII, la melancolía inmovilizada de las princesitas de Calderón, no pasaba de ser una tristeza continuada y penosa; hoy la neurastenia — eso era la antigua melancolía — tiene ramificaciones extensas y profundas» (Azorín, 1966: 173).

48 «La conciencia de pérdida, presente en el núcleo mismo del acto creador, de los actos de los creadores, es la causa de que entre ellos hallemos tantos hipocondríacos [...] llegando a modificar no sólo sus comportamientos personales o sus hábitos, como en cualquier hipocondríaco ocurriría, sino la naturaleza de la propia escritura» (Trapiello, en Aldecoa, 2001: 215-218). 
de lo cual tenemos muchos ejemplos en la obra de autores con dicho trastorno (Machado, Juan Ramón, Baroja...) (García-Posada y Trapiello, en Aldecoa, 2001: 16 y 211-230), como señalan los expertos:

...tengo la pequeña teoría de que el escritor, el novelista, es casi siempre, al menos en los tiempos que corren, un individuo de tendencia psicopática. Escribir novelas viene a ser una manera de escapar a la psicosis, de sortear una situación que empuja al desequilibrio y a la insania. [...] Creo que Baroja y Azorín eran dos depresivos [...] Baroja era un maniaco depresivo, y Azorín hace brotar toda su literatura de un estado de tenue depresión, sin fase maniaca. [...] En cuanto a la obra de Azorín, muestra toda ella la característica fuga de energía psíquica, sintomática, junto a otros rasgos azorinianos, de los depresivos encubiertos (Vaz de Soto, 1974: 156-158).

Por todo ello, en un artículo de juventud, el novelista elogia las dotes poéticas de Leopardi, propias de un temperamento melancólico ${ }^{49}$; describe a Sarrió en Antonio Azorín (1903): «embargado por esa melancolía indefinible que nos hace presentir las grandes catástrofes» (Azorín, 1943a: 330) ${ }^{50}$; o, en Las confesiones de un pequeño filósofo (1904), relaciona el talante español -obsesionado por la muerte - con el paisaje: «nuestra melancolía es un producto... de la sequedad de nuestras tierras; y la idea de la muerte es su corolario inmediato, riguroso, de la melancolía [...] que domina con imperio avasallador en los pueblos españoles» (Granjel, 1958: 215). Ya maduro, Martínez Ruiz titula un capítulo de Lecturas españolas (1938): «Primavera, melancolía» (Azorín, 1962b: 141); sugiere que nuestro primer héroe literario fue melancólico: «Don Quijote había muerto, años hacía, de aflicción y tristeza. — ¿Murió de melancolía?- ${ }^{51} ; \mathrm{y}$, en un artículo titulado «La vida», retrata enfermos de este mal ${ }^{52}$, cuyos sentimientos conoce bien por ser los suyos, como demuestra al definir su vida sumida «en una melancolía y en un pesimismo suave» (Ruiz de la Cuesta, 1974: 56), pues: «El sentido del tiempo depende, para mí, del temperamento. He necesitado yo siempre la melancolía; sólo con la melancolía advierto la hondura —y la plenitud- del tiempo» (Azorín, 1960: 94). No es de extrañar que el novelista proyecte su carácter al entorno, caso de los: «Días

49 «Admiro a Leopardi sobre todos los poetas; admiro el genio [...] que a los veintitantos años, retirado en Recanati, ya había conocido los secretos de la ciencia y llevaba en sí el tedio inefable, la melancolía exquisita del que todo lo ha visto, del que ha agotado el supremo goce de conocer. Nada más estético, más esencialmente artístico, que esta melancolía, esta ansia de vivir del que muere, este anhelo hacia algo soñado, hacia el ideal que no perece» (Azorín, 1992: 88).

${ }_{50}$ Sarrió reaparece en Los pueblos (1905) en un capítulo dedicado a él.

51 Vid. Azorín [José Martínez Ruiz]. «La vida», $A B C .5$ de junio, 1942.

52 «Pedro estaba enfermo; se dirigía en su coche a un lejano manantial salutífero; era todavía joven y se encontraba, empero, avejentado, entrecano, marchitas las facciones, sin brillo en la mirada» (vid. referencia completa supra nota 52). 
melancólicos, íntimamente melancólicos del otoño!», destaque «la melancolía honda y desgarradora de esta canción popular» (Azorín, 1976b: 12 y 33); o dedique un capítulo a un «melancólico librero» (Azorín, 1943a: 917) en Valencia (1941).

En consecuencia, y a lo largo de su trayectoria, varios personajes encarnan esta afección: Félix Vargas, de Blanco en azul (1929): «...en sus ojos leemos una profunda tristeza. La tristeza del poeta es la misma que sentimos nosotros recostados en la barandilla del río» (Azorín, 1976c: 73); el protagonista de su novela Don Juan (1940) ${ }^{53}$ o el de Tomás Rueda $(1941)^{54}$ y, sobre todo, el alter ego del novelista - el protagonista de El enfermo (1943) - en quien el alicantino se proyecta: «no somos ya el autor de este libro, sino el propio Víctor Albert y Mira» (Azorín, 2006: 69).

Los hipocondríacos suelen padecer males del alma o imaginarios, que acaban somatizándose, caso de Miguel de Unamuno, cuya angustia ante la muerte y su disolución le condujo a una pérdida de fe que nunca volvió a recuperar, causa de sus crisis de angor pectoris ${ }^{55}$ : «Las crisis anginoides que padeció Unamuno constituyen la respuesta carnal, orgánica, a las vivencias de angustia que le deparó la previsión de su propia muerte» (Granjel, 1960: 311-312) ${ }^{56}$. De modo parecido, Martínez Ruiz se interesa por las alteraciones del ánimo manifiestas en el cuerpo, comentando el libro del Dr. Huertas Barrero - La diabetes sacarina - dedicado a esta enfermedad que, en ocasiones, se origina por causas morales; es decir, cuando

...el espíritu domina la materia. Lo moral influye poderosamente sobre lo físico. Un hombre experimenta una profunda emoción; poco después, a consecuencia de ella, comienza a adelgazar; se presentan los primeros síntomas del terrible morbo, va rápidamente decayendo; muere. Las características de estas diabetes están profundamente conocidas. Las emociones, el estado de ánimo, la preocupación, los conflictos espirituales llegan a provocar fatalmente la enfermedad y a matar a un hombre (Azorín, 1966: 66).

53 «¿Hay, a veces, un arrebol de melancolía en su cara? ¿Matiza sus ojos, de cuando en cuando, la tristeza?» (Azorín, 1940: 18).

${ }^{54}$ «Sí, decididamente, en este mohín hay algo de meditación y de melancolía» (Azorín, 1941: 28).

55 En carta a Maragall de 15/2/1907, Unamuno confiesa: «Aquí donde usted me ve, sano y fuerte, he pasado por eso, por la preocupación de la angina de pecho, de un mal cardíaco, y conozco los males imaginarios. Mi mujer me curó de ello» (Unamuno y Maragall, 1951: 56).

${ }^{56}$ En un artículo Unamuno reconoce: «Escribo de las cuatro pestes del mundo, no como médico, sino como enfermo que las ha padecido. Temo (en esto, por lo menos, acierto) que antes me temerán por el contagio que me estimarán por la doctrina» (Miguel de Unamuno. «Comentarios quevedianos», Ahora. 16 de junio, 1935), y menciona su «novela quirúrgica Abel Sánchez», donde «ensayé en mí mismo la pluma-lanceta con la que escribí» (Unamuno, 2006: XL). 
La misma capacidad del sujeto para autoprovocarse la enfermedad, sin embargo, puede ser usada para hacerla remitir y Azorín asegura la fiabilidad de la autosugestión como método capaz de curar una dolencia. A modo de ejemplo, el alicantino menciona a Emilio Coué, farmacéutico que aconsejaba a sus clientes enfermos: «Es preciso que se cure usted. No lo olvide; repítalo; cúrese usted» (Azorín, 1966: 104). Dicho boticario no dejó libros escritos, sólo una breve conferencia titulada «El señorío de sí mismo y la autosugestión consciente ${ }^{57}$, de la cual Azorín cita algún aforismo:

«No empleéis vuestro tiempo en escudriñar las enfermedades que podáis tener; porque, si en efecto, no las tenéis, os las crearéis artificialmente»; «Vuestras manos tiemblan; vuestros pasos son inciertos. Decid que todo esto va a desaparecer, y desaparecerá»; «Contra la opinión generalmente admitida, la sugestión o la autosugestión pueden traer la curación de lesiones orgánicas»; «todo lo puede la voluntad» (Azorín, 1966: 105-106).

¿Cómo combatió la melancolía Azorín? Podemos intuir los remedios que utilizó para tratar su enfermedad conociendo aquellos que eligieron sus personajes. Nuestro autor los ha perfilado en muchas novelas, como el Antonio Azorín de La voluntad que, a falta de pasión o erotismo, se dice acompañado de «un amor intelectual, de un afecto, vago y misterioso», de «esta simpatía melancólica — más que amor- de un espíritu por otro espíritu» (Azorín, 1943a: 106 y 117). Si el personaje descrito en «Primavera, melancolía», de Lecturas españolas, confiesa: «siento tristeza, una tenue e indefinible tristeza, invadir mi espíritu» (Azorín, 1962b: 144), Víctor Albert no solo se sabe melancólico sino que investiga sobre su mal, al que hoy los psiquiatras ponen nombre:

Víctor había leído muchos libros — antiguos y modernos - de patología. Sabía observarse y trataba de interpretar su destemplanza primaria por vía somática: el riñón, el corazón, la ataxia. Fundamentalmente, angustia ante la oscilación entre el amor de enfermar y la seguridad de estar enfermo. Esto tiene un nombre: se llama Hipocondría ${ }^{58}$. La Hipocondría — que cabe en la neurastenia ${ }^{59}$, que está «en

${ }^{57}$ Martínez Ruiz le dedica el capítulo Imaginación, en Los médicos (Azorín, 1966: 103-106), a propósito de su libro El dominio de nosotros mismos o La maîtrese de soi-même (Nancy, 1928), repitiendo lo dicho en El artista y el estilo: «La imaginación sigue su labor: no padecemos achaques y nos los buscamos con nuestras cavilaciones» (Azorín, 1946: 485).

58 «La Hipocondría es un síntoma que cabalga sobre la línea de unión de la vertiente psíquica con la vertiente somática; que puede deslizarse por la vertiente somática y convertirse en auténtica enfermedad orgánica y puede progresar por la vía psíquica y ser verdadera enfermedad mental (delirio hipocondríaco: sentirse realmente los intestinos podridos, el corazón agusanado, etc.). En tanto es Hipocondría, no es enfermedad orgánica ni enfermedad psíquica. Y cuando llega a ser una cosa o la otra deja de ser realmente Hipocondría» (Merenciano, 1947: 194).

59 En Los pueblos, leemos: «Y la neurastenia va creciendo, creciendo formidable, [...] y nosotros, ya perdidos, nos dejamos llevar, anonadados, de la corriente fatal que nos conduce a la anulación definitiva» (Azorín, 1943a: 332). 
las fronteras de la enfermedad ${ }^{60}$ - es síntoma predilecto de la Psicosis mitis (Merenciano, 1947: 193-194).

Dávila, en El escritor, depende de somníferos — «...se ve [...] junto al vaso un tubito de comprimidos contra el insomnio» (Azorín, 1957a: 65) - y Víctor Albert «Usa con exceso de medicamentos: los dormitivos "le dan primero lucidez y, luego, le calman dulcemente los nervios"» (Azorín, 2006: 105). Pese a ser consumidor de los fármacos al uso — «En un armario reposan ya cajitas de tabletas y frascos con varios medicamentos; no faltan las ampollas para inyecciones»-, Martínez Ruiz confiesa sentir «viva simpatía por estos remedios fenecidos» (Azorín, 2006: 125-126) — plantas y minerales - cuyas propiedades curativas menciona en Los médicos — «un hombre que se erigió en campeón de la ciencia y de la verdad, don Diego de Torres, en su libro Vida natural, nos recomienda que en la boca traigamos "algún jacinto, granate o bola de cristal, porque estas piedras tienen poderosa virtud contra el veneno y otras enfermedades"» (Azorín, 1966: 146) - y en la ficción, sea en un cuento de Blanco en azul — «Este doctor es un hombre muy sabio; conoce las propiedades de los simples ${ }^{61}$, de las piedras y de las plantas» (Azorín, 1976c: 106) o en su novela El enfermo, cuyo protagonista es buen conocedor del poder misterioso de las piedras contra la melancolía ${ }^{62}$.

Para tan inespecífico mal, la terapéutica más reiterada en las narraciones del autor ${ }^{63}$ es la ingesta de aguas y los balnearios. De hecho, el reconocimiento de la alteración psicológica de Martínez Ruiz lo hallamos en uno de los artículos que escribió el novelista desde el balneario de Solares ${ }^{64}$ : «Si por acaso estáis neurasténico y venís a tomar estas aguas, recomendadas para la

${ }^{60}$ «En los enfermos en las fronteras de la enfermedad importa mucho la psicoterapia y a Víctor Albert le ayudan sus médicos, que le controlan dulcemente, pues "al enfermo culto hay que dominarle desde la misma cultura". Los doctores de Víctor eran cultos; Víctor lo era más» (Merenciano, 1947: 182 y 219).

${ }^{61}$ simple 'material de procedencia orgánica o inorgánica, que sirve por sí solo a la medicina, o que entra en la composición de un medicamento' (DRAE).

${ }^{62}$ «En la Farmacopea matritense, que está leyendo Víctor, todavía se preconiza el uso de las piedras preciosas: la esmeralda, el topacio, el jacinto, el granate. El granate es eficaz contra la melancolía; supone Víctor que también lo es el rubí. El magnífico rubí, como henchido de jugo de granada, que ciñe Víctor en su dedo, tal vez dé a Albert esta su constancia en el trabajo y esta su serenidad en las adversidades» (Azorín, 2006: 126).

${ }^{63}$ «Pedro estaba enfermo; se dirigía en su coche a un lejano manantial salutífero; era todavía joven y se encontraba, empero, aventajado, entrecano, marchitas las facciones, sin brillo en la mirada» (vid. referencia completa supra nota 52).

${ }^{64} \mathrm{E}$ l autor redactó una serie de crónicas (Veraneo sentimental) describiendo su estancia en distintos balnearios del norte de España (Cestona, Urberuaga, Zaldívar, Solares, Carranza, Ontaneda, Caldas...), mostrando la psicología de sus visitantes y su vida en ellos. $\mathrm{Pu}$ blicadas el verano de 1904 en el diario España (11/7/1904 a 15/8/1904) y en libro, en 1929. Vid. nota 65 . 
neurastenia, no podéis haber caído en un paraje más adecuado a vuestro achaque» (Azorín, 1929: 92). En Los pueblos, y hablando de los centros termales, el novelista puntualiza que no son lugar de veraneo sino centros para enfermos ${ }^{65}$. Quien así lo afirma los conoce bien — «Los balnearios son una cosa triste: comienzo a comprenderlo» (Azorín, 1929: 169-172) - y de ahí su comentario: «¿Desconoceréis acaso la virtualidad de estas aguas? [...] ¿No sabéis que a estos manantiales acuden los enfermos estéticos ${ }^{66}$, en la verdadera y primitiva acepción de esta palabra?» (Azorín, 1943a: 367). También, fuera de dichos centros, los personajes de Martínez Ruiz ingieren agua sanadora, tanto Víctor Albert, en El enfermo — «agua alcalina» calificada de «salutífera» (Azorín, 2006: 70)—, como Dávila, en El escritor: «...se ve a cierta altura un vasar. Seis botellas de agua alcalina se enfilan allí» (Azorín, 1957a: 65).

Por último, Azorín dedica un capítulo de Los médicos -Neurastenia preferida - a tratar ese «no tengo nada y tengo algo» que angustia al novelista; mal que aqueja al hombre «que no tiene nada [...] y, sin embargo, está enfermo», que siente «un cansancio, una desilusión de todo»; sea tedio, desamor o profunda tristeza, siendo el único remedio: «el trabajo, un trabajo moderado, higiénico» (Azorín, 1966: 78, 79 y 83), pues: «¡Cuántos neurasténicos hay por no trabajar mucho, y cuántos por no trabajar nada!» (Azorín, 1966: 83).

\section{AZORÍN, ANTE SU ENFERMEDAD}

Ya hemos visto cómo algunos médicos, estudiosos de Azorín, han sugerido que la causa de su atracción por la enfermedad sea la de entender la propia ${ }^{67}$ : «le obsesionaba la enfermedad, sus amigos los médicos, las medicinas» (Ruiz de la Cuesta, 1974: 56). De hecho, en la nota introductoria de El político, el novelista confiesa: «He escrito estas páginas durante una larga convalecencia,

65 «El bañista no es un veraneante: es un enfermo» sometido a «operaciones enojosas que es preciso realizar y sufrir todos los días: el baño, las pulverizaciones, las inhalaciones, las vaporizaciones, la toma de agua en bebidas [...] en un ambiente de éter, de cloruro, de vapor escapado de las pulverizaciones...» (Azorín, 1943a: 383-384).

66 En El enfermo, se lee: «-Hay en usted una cierta apetencia a los medicamentos. Y la hay, pásmese usted, por el aspecto estético de esos mismos medicamentos [...] le entusiasman a usted las cajitas primorosas, los frascos brillantes, las ampollas de inyecciones [...] - Predominaba lo estético, y conseguía con ello, a veces, un efecto de sugestión» (Azorín, 2006: 184-185).

67 «La introyección abre la puerta en quien la vive, en ocasiones, a la derivación neurótica; sin pretender asegurar que Azorín lo sea o lo haya sido un día, sí es bien cierto que su personalidad, tal como ella se descubre, con singular frecuencia, en el cuerpo de su obra, ofrece rasgos que autorizan a sospechar su presencia» (Granjel, 1958: 112 y 115). 
en el campo» (Azorín, 1919). Además de su neurastenia, y una dislalia ${ }^{68}$ sumada a una ligera torcedura del labio inferior, Azorín padeció una cardiopatía, según confesión de su médico, que condicionó su vida y carácter:

...saqué a la luz pública, cuando mi relato ya no podía perjudicarle en ningún sentido, una enfermedad que padeció [...] De tal proceso orgánico, diagnosticado primero por Juan Madinaveitia, me pusieron al corriente Marañón, al encargarme le atendiera profesionalmente de su corazón, y su médico de cabecera, don Manuel Izquierdo. Pocos días más tarde y en muy privada conversación me lo contó el propio Azorín con más detalles y con exquisita sencillez. Le asistí desde el 28 de febrero de 1963 hasta la fecha de su muerte (Vega-Díaz, 1987: 105).

Tal vez por ello, Martínez Ruiz, siempre temeroso y preocupado por sus males físicos, buscó consejo en galenos o en lecturas sobre medicina ${ }^{69}$, llegando a reunir un considerable compendio de conocimientos ${ }^{70}$. De él parte para descubrir el significado de sus molestias y elaborar una terapéutica personal ante la vida, alejado de la farmacopea y convencido de que «la salud no está en los frascos ni en los tubos, sino en la naturaleza, en la objetiva y en la subjetiva, en la de fuera y en la nuestra» ${ }^{71}$, diseñando pautas de higiene, horas de trabajo $^{72}$, sueño ${ }^{73}$, hidroterapia ${ }^{74}$ y remedios sencillos cuando ya la

68 «Azorín tenía un ligero defecto en la pronunciación. No podía pronunciar la k ni la q. Las consonantes linguo-velo-guturales [...] En terminología médica es una dislalia, del gran grupo de las afasias; un defecto en la articulación de la palabra, debido a una mala pronunciación de las consonantes» (Vega-Díaz, 1987: 105-106).

${ }^{69}$ Fue seguidor del microbiólogo I. Ilich Metchnikoff (1845-1916), Premio Nobel de Medicina en 1908.

${ }^{70}$ En El alma castellana, hablando del café, refiere: «Cuéntase entre los impugnadores a Isidro Fernández Matienzo, que en 1693 publicó su Discurso médico y phisico agradable a los médicos ancianos y despertador para los modernos contra el medicamento caphé» (Azorín, 1959a: 592-593).

${ }^{71}$ En La isla sin aurora, el autor se reafirma: «No cambiarías tu, ni yo tampoco, el aire, el agua, las plantas salutíferas, el ejercitar los músculos en el bosque, la temperatura clemente, el orden y la limpieza en la vida, por todos estos frascos y todos estos tubos en que, según dicen, reside la salud» (Azorín, en Granjel, 1958: 324).

72 «Cada madrugada — sobre las dos, sobre las tres - escribo unas cuartillas» (Azorín, 1960: 57).

73 «En Francia, dice, ni el sustento ni el sueño — cosas tan esenciales- son idénticos a los de España [...] El sueño no puede ser el mismo — no puede ser tan plácido—, siendo distinto el modo de las camas» (Azorín, en Manso, 1993: 175).

${ }^{74}$ «Las aguas son sin disputa delgadísimas. Yo, aunque he leído algo sobre el análisis de ellas, nunca he intentado analizarlas. Quise sí, por medio del hidrométrico, hacer comparación de unas con otras, y se quedó en especulación. Ignoro sus virtudes; no sé si son acículas, o si con sus sales neutras emprenderán los físicos la cura de algunas enfermedades y dolencias. Mientras [...] diré yo, con su licencia, que he observado en ellas las señales que las caracterizan de buenas, según los naturalistas. No tienen olor, sabor, ni color» (Azorín, 1976a: 118). 
enfermedad se ha manifestado (el vinagre contra la fiebre ${ }^{75}$, el cocido casero $^{76}$, etcétera).

Nuestro autor defenderá una medicina aplicada al caso individual y nacida del propio criterio del enfermo a partir de sus observaciones. Si, en Pensando en España, afirma rotundo: «No existe el mal en abstracto. Lo que existe son enfermos...» (Granjel, 1960: 325), en Los médicos, concluye: «el sujeto ha de preparar la labor del médico con su propia observación; el primer médico del enfermo es el mismo enfermo» (Azorín, 1966: 25). Convencido de su filosofía, basada en el autoanálisis como norma de vida, Azorín la expondrá en artículos («La medicina» $)^{77}$ y libros (Los médicos $)^{78}$.

Tampoco olvida este escritor contemplar un régimen alimentario ${ }^{79}$ basado en la sobriedad: sea evitando el alcohol ${ }^{80}$, cuyos efectos conoce bien, así como

75 En Superrealismo, se lee: «Con unas gotas de este maravilloso vinagre en un vaso de agua fresca se apaga la sed para mucho tiempo, y si estuviéramos un poquito febriles, desaparecería al punto la calentura» y, en Valencia: "Con unas gotas en un vaso de agua se quita la fiebre y se refresca el cuerpo» (Azorín, 1943a: 852-853 y 908).

76 «De día y de noche, a toda hora, se encuentran cuartos de gallina, carne y garbanzos para pucherito de enfermo en la plaza de las Yerbas» (Azorín, 1943a: 916). En el Manual de forasteros en Valencia, de José Gárrulo, se menciona la receta como Recado para puchero enfermo.

77 «En el conocimiento físico, lo que importa es hacer un estudio detenido de nuestra psicología particular y de nuestra patología [...] "cada hombre es un mundo"» (Azorín, 1976a: 69 y 70).

78 «...cada hombre es un mundo, y cada cual necesita su higiene y su terapéutica especiales..., que no son la terapéutica y la higiene de los demás. Y, sobre todo, tenga usted entendido que en medicina y en higiene no existen más que tres o cuatro cosas en las que se puede creer [...] el sol, el aire y la limpieza. Mi credo médico, así de un modo casi dogmático, se reduce a esto. [...] la norma de estudiar al enfermo, con preferencia a la enfermedad, no es de ahora, sino que viene de muy atrás. Siempre se ha preocupado el buen observador más del enfermo que de la abstracción llamada enfermedad. Recuerdo que nuestro Feijoo, que también nombra a Sydenham, dice en el discurso titulado El médico de sí mismo las siguientes palabras, que copio de la edición añadida de 1765: "Uno de los principios de la incertidumbre de la Medicina es la diferencia individual de unos hombres a otros, por lo cual frecuentemente lo que a unos aprovecha a otros daña". No se puede marcar, con más claridad, la individuación en la ciencia médica» (Azorín, 1966: 12, 24 y $160)$.

79 En Soledades, el novelista incluye varias afirmaciones sobre la dieta: «come bien y serás honrado», «Los pueblos que mejor comen son los más cultos» (Azorín, 1959a, I: 336 y 345$)$.

${ }^{80}$ «Una de sus preocupaciones es combatir el uso inmoderado del alcohol que hacen estos pobres labriegos en la taberna. No hay nada como un vaso de agua pura y límpida. En Riofrío huyen del agua. "Temen estas gentes tanto al agua, que se estremecen al verme echar a pechos por la mañana un vaso". El vaso bien fregado, limpio, lleno de agua exquisita» (Azorín, 1976b: 96). 
su tratamiento ${ }^{81}$ o los excesos en la mesa; denunciando que comemos «en proporciones aterradoras» (Azorín, 1966: 148) y que deberíamos imitar a los cartujos en frugalidad y dieta:

Lo que da realmente fortaleza no es sólo la sobriedad, sino la alimentación vegetal. Verduras y frutas hacen que el hombre viva sano. [...] Y no es sólo el capítulo de la alimentación el que debe preocuparnos. El dormir es cosa esencial. [...] Un rato cuotidiano de ejercicio en pleno aire tonifica los nervios [...] La deambulación en pleno aire inclina a la tolerancia... (Azorín, 1966: 150-151).

En sus Memorias inmemoriales (1946), el alicantino reconoce que su práctica del vegetarianismo fue tardía: «En su juventud, X se afanaba por la carne; en su vejez ni probaba carne ni pescado. Le preocupaba mucho el alimento que había de ingurgitar» (Azorín, 1948: 362) y, el diseño de un plan de vida, tomará medidas drásticas para llevarlo a cabo, como renunciar a las sesiones de la Real Academia, por no alterar su horario ${ }^{82}$. Ser fiel a una dieta ${ }^{83}$, pese a circunstancias como el exilio, fue una actitud que nació en el novelista de una exigencia de autoperfección y austeridad en el vivir para sentirse fuerte ${ }^{84}$ (Rico Verdú, 1973: 72):

Las comidas que he ingerido durante tantos años, en la niñez, en la juventud, son las comidas que ansío. El cuerpo manda en nosotros [...] Se ha habituado el cuerpo, desde la infancia, a recibir tales alimentos, y esos alimentos se reclaman con ansiedad en la edad provecta. Todo esto quiere decir que yo no cambio mis

81 «...murió de un ataque de delirium tremens. [...] sé yo lo que hago; conozco a lo que me expondría si beborroteara. No llegaré a que se haga ineludible en mi persona, a causa de un estado de alcoholismo crónico, el tratamiento por la estricnina» (Azorín, 1943b: 96).

82 «Hay una causa que es un obstáculo para mi asistencia a la Academia: la hora de las juntas o sesiones. Esa hora es la de las ocho, y esa hora es cuando yo hago mi postrera refracción. No la tomo a otra hora por nada del mundo. Media hora después, estoy metido entre sábanas. Y al comienzo de la madrugada principio a trabajar. La asistencia a la Academia trastoca, por tanto, mi vida cotidiana» (Azorín, 1948: 408-409).

${ }^{83}$ Dado que el comer «es un acto accesorio, [...] ingiero lo que he experimentado que me conviene y en la cantidad que me conviene. No cedo nunca, en una mesa fastuosa, a la tentación. [...] verdura cocida, apenas aliñada con aceite y sal, y las legumbres, y las frutas. ¿Y para qué quiero más?» (Azorín, 2006: 71 y 134-135).

84 «Hay en él un afán de perfeccionamiento, de ascetismo, que no es ni más ni menos que la negación de su propia personalidad. Al no aceptar su yo, tiende a cambiarlo, mejorándolo mediante actos ascéticos, por otra personalidad más perfecta. Esta misma tendencia le lleva, por otra parte, a sobrevalorar las cualidades positivas que ve en sí, esto es, a su narcisismo. Se ha dicho que Azorín posee un yo hipertrofiado; esto es falso, puesto que el yo es como es y no puede atrofiarse ni hipertrofiarse. Junto a la visión negativa de sí mismo, Azorín necesita su propia afirmación, la cual viene dada no por una preocupación de adquirir cosas para sí (egoísmo), sino de contemplarse y admirarse a sí mismo» (Rico Verdú, 1973: 57). 
yantares nativos por todas las delicadezas coquinarias de Francia (Azorín, en Manso, 1993: 175).

En suma, Azorín sintetiza en cuatro normas su plan vital: «Todos debemos estudiarnos y todos debemos poseer, como resultado de nuestro estudio, un canon de vida y una terapéutica. [...] ¡Sepamos callar, sepamos dormir, sepamos respirar, sepamos comer!» (Azorín, 1966: 106 y 152). Esta sana pauta también tiene en cuenta la temperatura ambiente, como expone el autor en sus Memorias, donde analiza lo que supuso para los noventayochistas «El clima de Madrid». En el capítulo así titulado, el novelista relaciona la temperatura y la altitud con el malestar vital de los escritores del momento:

[el Dr. Cazenave dice que en Madrid]...de un momento a otro cambia el termómetro. Estas perturbaciones motivan un «estado neuropático muy particular, que se traduce por una irritabilidad del carácter, una inquietud de humor, un desasosiego nervioso» [...] Tal espíritu de oposición era el espíritu de los escritores del consabido grupo. Y el desasosiego doloroso que señala el climatólogo francés, era su desasosiego (Azorín, 1943a: 989-990).

Por último, Martínez Ruiz entiende el proceso de envejecimiento como una enfermedad inevitable que altera las funciones corporales ${ }^{85} \mathrm{y}$, en relación a esta etapa de la vida, cita al académico Dr. Amalio Gimeno (1956), que trata el «problema» de la vejez, el modo de combatirla y lo que «la ciencia nos dice respecto a este término fatal» (Azorín, 1966: 29):

En la sobriedad, en la templanza, está, por lo tanto, para nuestro autor, el secreto de la longevidad. Por el contrario, en los excesos, en la intemperancia, en las comidas largas y suculentas, en las bebidas refinadas y copiosas se hallan los gérmenes de todos los males y la muerte. [...] En resumen la doctrina de nuestro Dr. Gimeno se reduce a «la de comer muy poco» [...] [porque] El problema de la vejez es un problema de limitación: limitación, sobre todo, en la mesa; de otras restricciones no es preciso hablar (Azorín, 1966: 32, 35 y 26).

Interesado por los cuidados a los que el anciano debe ajustar su conducta ${ }^{86}$, nuestro autor se observa para darse cuenta de qué le sienta mejor o qué le

${ }^{85} \mathrm{Y}$ trata el tema en artículos («El arte de vivir», La Prensa. 8 de noviembre, 1936) y en dos capítulos de Los médicos — «Ser viejo» y «La vejez»—. En este último, afirma: «Un fino psicólogo, un duque, La Rochefoucauld, ha dedicado en sus Máximas tres por lo menos a la vejez» — de las que cita una: «“Al envejecer nos hacemos más cuerdos y más locos”» (Azorín, 1966: 184).

${ }_{86}$ «Al llegar a la senectud todo ser humano, si es un tantico inteligente, debe tener recopilada su experiencia de la vida. Todo a lo largo de los años habrá ido estudiándose a sí mismo. Estudiarse a sí mismo es darse cuenta de lo que nos sienta mejor, en cuanto a mantenimientos, de los lugares, montaña o mar, qué nos conviene más, del régimen de silencio discreto y de dormir sosegado que nos han traído tantos bienes. [...] Cuando un mal 
conviene; y estudia los cambios que provoca en el sujeto. No se refiere el autor a la inevitable pérdida de hábitos debidos a la edad - como las diferencias de interés y actitud del joven y el viejo ante la lectura- ${ }^{87}$; sino del cambio que sufre la personalidad del sujeto enfermo, que es distinta desde que lo está, como reconoce en su libro de memorias Valencia (1941):

«Amamos con sincero amor a una persona enferma, y esta persona, gradualmente, casi imperceptiblemente, de año en año, de mes en mes, se va transformando a causa de su enfermedad. Hemos comenzado teniendo una imagen de la persona, y la imagen va cambiando. [...] Es el mismo ser querido y no es el mismo, no» (Azorín, 1943a: 867-868).

Nuestro escritor, sin embargo, señala una ventaja para quien sufre de un mal y es eximirle de los convencionalismos sociales, algo muy deseable para Martínez Ruiz dada su timidez, igual que para su personaje, Víctor Albert: «El estar enfermos nos excusa de muchas obligaciones sociales; podríamos, en rigor, cumplirlas; pero nos zafamos de ellas con nuestra dolencia. No puede un enfermo hacer visitas, ni escribir respuestas a cartas enfadosas, ni asistir — ¡y qué bueno es esto! - a conferencias» (Azorín, 2006: 172).

\section{ENFERMos EN LAS NOVELAS DE AZORÍN}

Conocido el sentir de Martínez Ruiz ante su enfermedad y las medidas que adopta al respecto, es mucho más fácil entender a diversos personajes de sus novelas, meras proyecciones de su creador ${ }^{88}$, obsesionado con dolencias y mé-

nos aqueja, sin pensar en su motivación, sin cuidado de sus antecedentes, vamos corriendo al médico o el médico viene a nuestra casa. Reponemos nuestra salud, cuando la reponemos, y tornamos al mismo modo de vivir compulsivo e irreflexivo. [...] no nos fijamos en lo que comemos. Charlando animadamente, se mastica a la ligera. Con la masticación imperfecta se originan multitud de quebrantos. Se come, además, mucho. No se come, se engulle. Para vivir con fortaleza y sanidad basta una leve porción» (Azorín, 1966: 149).

87 «En la vejez ya no podemos leer tanto como antes; pero tenemos una ventaja: releer es leer por primera vez. Se reduce el número de lecturas. [...] La lectura no es lo mismo a los veinte años que a los 60. El joven lo lee todo y de todo aprovecha poco. El anciano lee poco y de lo poco lo aprovecha todo. Con la edad, las lecturas se van reduciendo. [...] Reduce sus lecturas a lo selecto del mundo. Sólo los grandes autores merecen su elección. Ve entonces en ellos lo que no veía a los treinta años» (Azorín, en Díaz-Plaja, 1967: 54).

${ }^{88}$ La mayoría de personajes enfermos son variaciones sobre el patrón del neurasténico en que se contempla el autor: «Los enfermos de las obras de Azorín padecen dolencias más imaginadas que reales y su perfil es parecido: hombres de letras, o artistas, preocupados por el problema del tiempo, como el autor. Más que enfermedades padecen neurosis» (Granjel, 1960: 326). 
$\operatorname{dicos}^{89}$. El primer personaje enfermo del autor —en su obra de juventud Buscapiés (1894) - es Luis M. a Munáriz, cuya situación vital le empuja a leer tratados de patología, lo cual no evita su suicidio.

La crítica ha señalado que la dolencia del protagonista de Diario de un enfermo (1901), lejos de ser una patología fisiológica, es una metáfora de la crisis individual y de toda una época — el mal del siglo ${ }^{90}$ - , pues la enfermedad del alma que aqueja a este personaje está causada por la sociedad burguesa que le rodea, también enferma, y representa un estado carencial que conlleva sufrimiento y soledad. Hastío ${ }^{91}$, tristeza, ennui, monotonía, abulia, spleen...$^{92}$ son formas de aludir a esta crisis del sujeto ante el sinsentido de la existencia que provoca la disolución de su personalidad.

Más allá de la enfermedad como metáfora, el escritor de Diario de un enfermo encarna a un «verdadero neurótico, en quien alternan crisis de excitación con otras de depresión y abulia» (Granjel, 1960: 327). Carácter de sensibilidad hiperestética y decadente, este artista busca al lado de su amada tuberculosa refinadas sensaciones ante la muerte. Tras su deceso, y hundido psicológicamente, sufre escindido en un dilema angustioso entre vivir o pensar. Su enfermedad, sin embargo, posee un aspecto positivo en la medida que supone un elogio del desequilibrio fértil y anormal, de lo singular frente a la vulgaridad de la masa.

El protagonista de Antonio Azorín (1903) aprende a vivir con dignidad, a pesar de su nihilismo, con una actitud contemplativa, sin voluntad, sin lucha, afrontando estoicamente el sufrimiento y estando a la altura de las circunstancias. Guiado por maestros como Gracián, el autor hará posible que sus pos-

89 En El enfermo, son varios los capítulos dedicados a los doctores que tratan al protagonista: el XVI, al Dr. García de Rodas; el XVII, al Dr. Facundo Irala, especialista en enfermedades del estómago; el XXII, a Fermín Satorres, practicante y barbero; el XIII, a Primitivo Miralles; el XXIV, a Alfredo Landeira, que sustituye a Miralles al morir; el XXVII, titulado Médicos, insiste en su querencia por los dos primeros; el XXXII, a Don Laureano Vera, que suple a Landeira.

90 «Existe en la sociedad moderna un mal que, aunque no registrado en los más perfectos tratados de patología, hace víctimas numerosas en las filas de la juventud estudiosa. Es este el hastío temprano que atrofiando la voluntad y aplanando el espíritu, agosta los más entusiastas ideales y derrueca los caracteres más bien templados» (Azorín, 1959a: 71).

91 Título de un relato del alicantino en Buscapiés (1894), libro donde se dan distintos nombres a esta «enfermedad», junto a «Vencido», cuento que presenta la crisis del genio ante el problema de la creación en un pintor que persigue la fama, como el intelectual de Diario de un enfermo.

92 «Lo que nosotros designamos con el nombre de spleen y que los místicos denominan "momentos de entorpecimiento", ya era conocido en la Edad Media como acedia (apatía) [...] se trata de una enfermedad típica del hombre que ha alcanzado el grado supremo del aislamiento y decide maravillosamente el mal» (Kierkegaard, 1993: 53). Así se expresa George Sand: «Tengo el spleen, tengo en el alma la desesperación [...] este hastío de todo, este aburrimiento devorador» (Sendrail, 1983: 366). 
teriores personajes vivan «enfermos» pero aceptando el sinsentido de la existencia con entereza, tras entender que asumir la crisis es el único modo de sobrellevarla.

En Pueblo (1930), el narrador confiesa que «A veces, es tan honda la sensación de soledad, que nos sentimos respirar y llegamos a un jadeo angustioso», lo cual no impide gozar, «al mismo tiempo, la complacencia tan íntima de este silencio, de esta quietud, de esta majestad» (Azorín, 1957b: 95). Si, en Tomás Rueda (1941), la enfermedad del personaje altera su carácter que «ahora era vidrioso, un poco vidrioso. Se irritaba fácilmente...» (Azorín 1941: 121); en El enfermo (1943), el protagonista padece de «semiletargia» pues «somos otros de los que antes éramos. Hemos perdido una personalidad y hemos ganado otra. Y esta otra vale acaso, y sin acaso, más que la precedente» (Azorín, 2006: 189 y 169); y, en «El primer milagro», de Blanco en azul (1945), se califica de «Locura pacífica» el trastorno del protagonista (Azorín, 1976c: 106).

También el afán desmedido por los libros que padecen los protagonistas de las novelas juveniles de Martínez Ruiz es visto como patológico: -el de Buscapiés (1894) igual que el de Diario de un enfermo (1901) $)^{93}$ - El exceso y la consecuente aversión a la lectura, por ser producto de la mente, expresa el vitalismo finisecular y la reacción del novelista después de haber sido un lector voraz, como reconoce su alter ego en La voluntad y en Antonio Azorín ${ }^{94}$. En sus memorias — Madrid (1941) — , sin embargo, nuestro autor confiesa no haberse curado aún de este mal: «No he podido zafarme de los libros tampoco. Escribir y leer son cosas terribles. Y mucho más el pensar» (Azorín, 1943a: 956), igual que los personajes de sus novelas de madurez —Tomás Rueda $(1941)^{95}$, El escritor (1942) ${ }^{96}$ o El enfermo (1943) (Granjel, 1958: 87)—; la

93 «Diario de un enfermo profundiza en los aspectos de la vivencia íntima y existencial de la angustia, nos ofrece la historia interior de un alma enferma, la herida del espíritu contada desde dentro» (Martín, en Martínez Ruiz, 2000: 58 y 61).

${ }^{94}$ En La voluntad leemos: «Otra de mis preocupaciones eran los libros. Yo he sido también un formidable erudito: lo leía todo, en pintoresca confusión, en revoltijo ameno: [...] Tenía fe en los libros; los compraba a montones... y poco a poco he ido viendo que en el fondo todos dicen lo mismo, y que con leer cincuenta - y creo que es mucho- se han leído todos» y, en Antonio Azorín: «Los libros son falaces; los libros entristecen nuestra vida» (Azorín, 1943a: 174 y 242).

${ }_{95}$ «No quería ya los libros; no pasaba sobre ellos las horas. [...] La sabiduría está en la vida y no en los libros. Nada nos enseña tanto como este ajetreo por aldeas y ciudades» (Azorín, 1941: 92).

96 «No leo ahora tanto como antes; no lo leo todo; Dávila replica que él lee libros abondo, sin mirar lo que lee y sin hacer antes una selección previa [...] yo le digo que la lectura ahora, para mí, es parca, porque deseo ahorrar fuerzas; leo pocos autores; siempre los libros han variado, para mí, creo que varían para los demás, según se lean en uno o en otro día, con salud o con enfermedad, en momentos placenteros o en momentos dolorosos» (Azorín, 1957a: 85). 
última de las cuales muestra la «dolencia» a la que llega el protagonista como consecuencia de leer y escribir sin límites: «Víctor vive la vida muerta, la vida de los libros ${ }^{97}$ (Azorín, 2006: 80), aunque asegure leer con mayor aprovechamiento:

El deseo de meditar, la complacencia en el meditar, van ganándome a mí por grados; conforme avanzo en la vida leo menos y medito más; en realidad, el fruto de la lectura no es menor ahora — cuando leo menos libros- que antes; leía antes más libros, leía sin cesar libros y libros, y de todos ellos sólo quedaba en mí una porción pequeña, acaso lo esencial; [...] los pocos libros que ahora leo los aprecio en todos sus matices y encuentro en ellos accidentes y circunstancias en que antes no reparaba. Todo ello, naturalmente, es resultado de la meditación (Azorín, 1957a: 135).

Como sus entes de ficción, Martínez Ruiz reconoce su mal en Un pueblecito, Riofrío de Ávila (1946):

Tanto leer no puede ser bueno. Tú mismo lo conoces, y experimentas los efectos de la melancolía producida por la lectura. Tanto leer no puede ser bueno. Pero ¿qué vas a hacer si no lees? ¿Qué vamos a hacer — tú, yo y otros tantos- si no leemos a filósofos, poetas, literatos, autores de todo género y catadura? Leer: ese es nuestro sino. [...] La prisión es nuestra modalidad intelectual; es nuestra inteligencia; son los libros. Cuando salgas de ahí, te encontrarás igualmente prisionero en Madrid o en Salamanca. Serás prisionero de los libros que tú amas tanto. De los libros somos prisioneros todos nosotros (Azorín, 1976b: 148).

Otra «enfermedad» que parece afectar a los personajes azorinianos es el Síndrome de Florencia o «estrés del viajero», dolencia psicosomática que causa un elevado ritmo cardíaco, vértigo, temblor, cuando el individuo se halla ante obras de arte, especialmente bellas, o expuestas en gran número. También conocido como síndrome de Stendhal, por ser este autor quien dio una primera descripción del fenómeno tras experimentarlo ${ }^{98}$, se ha convertido en un referente de la reacción romántica ante la acumulación de belleza y la exuberancia del goce artístico. Azorín se identifica tanto con un edificio antiguo o un cuadro como con el sentimiento de un personaje del pasado en el que se reconoce $^{99}$, dado que «las emociones de otros hombres en otros tiempos pueden ser

97 «Lleva 50 años escribiendo Víctor Albert; cuenta 70» (Azorín, 2006: 104).

$98 \mathrm{G}$. Magherini fue la primera en poner nombre al sindrome, en su libro El sindrome de Sthendal (1989), aludiendo a lo narrado por Henri-Marie Beyle, más conocido por su seudónimo Sthendal, en sus notas de diario: Nápoles y Florencia: Un viaje de Milán a Reggio contando su experiencia de 1817 en la Basílica de la Santa Cruz de Florencia.

${ }_{99}$ Azorín se identifica con Proust, porque «posee una prodigiosa memoria de sensaciones. A distancia de diez, quince, veinte años, puede volver a sentir una sensación con toda la viveza y plasticidad originarias» (Azorín, 1959b: 92) y cita A la sombra de las muchachas en flor, I, pp. 51-52, donde el autor francés describe la operación. 
para nosotros espectáculo inmediato y tan real como el paisaje que ahora existe ante nuestros ojos» (Ortega, 1954: 165). Dicho sinfronismo ${ }^{100}$, o «coincidencia de sentido» entre hombres de épocas diversas, lo experimenta el personaje de Diario de un enfermo ante la tumba de Larra; el busto de Santa Teresa, que despierta su misticismo, o un lienzo: «Este divino Greco me hace llorar de admiración y de angustia» (Martínez Ruiz, 2015: 287); igual que, en La voluntad, Antonio Azorín reconoce: «siento algo indefinible en las callejuelas de Toledo, o ante un retrato del Greco u oyendo música de Victoria» (Azorín, 1943a: 93).

En este sentido, la primera novela de Martínez Ruiz supone -más que el diario de unos sucesos - el seguimiento de un malestar espiritual, al describir la incertidumbre de un hombre angustiado, y la depresión de una esperanza que se esfuma, en los que se retrata el autor. Su neurosis es el mal que aqueja también a Pablo de Silva en Doña Inés - cuya dolencia, aunque imaginaria, perturba su existir - ; a Víctor Albert en El enfermo quien, como ellos, vive su mal (real o imaginario) somatizándolo; o al protagonista de Superrealismo, descrito como «un pobre enfermo que no puede reposar» (Azorín, 1943a: 855).

Este personaje, al leer una biografía sobre Hoffmann, identifica sus síntomas con los del novelista germano y llama a su achaque - que le impide vivir el presente- mal de Hoffmann ${ }^{101}$ (Granjel, 1960: 329). Sus síntomas son: ver en el ahora el pasado o el anuncio del futuro ${ }^{102}$, desdichados estados de desaliento, sequedad y vacío espiritual, con incapacidad de pensar o escribir; alternos con otros, esporádicos, de exaltación intelectual y capacidad creativa. Lo mismo le ocurría al neurótico protagonista de Diario de un enfermo, en quien se sucedían crisis de excitación creativa con otras de depresión y abulia, en las que se adivinaba el trasfondo autobiográfico del autor. Estos cambios en la sensibilidad del artista llevan a Azorín a preguntarse «¿Es este acaso el período de sequedad, como lo hemos nombrado, de que hablan los místicos?» (en Granjel, 1960: 329). La misma neurosis aqueja a Pablo de Silva, o a Víctor Albert..., siendo el temple vital lo que primero se ve disminuido en todos, al

100 «En su celebrado ensayo sobre Azorín, Ortega y Gasset recuperó el concepto goethiano de sinfronismo (o "coincidencia de sentido, de módulo, de estilo") entre personas de épocas distintas como una de las claves para comprender su arte» (Selva, 2012: 244-245).

101 «La lectura de la biografía de Hoffmann hizo aflorar en la conciencia de don Pablo lo que estaba latente en lo profundo... Y ya desde aquel día, el mal oculto fue ostensible» (Merenciano, 1947: 114).

102 «Para el poeta es un tormento el regresar desde el momento presente al pretérito. Tiene la superstición del tiempo; la evocación del pasado le agobia; diríase que el evocar el pasado, su pasado - la niñez, la adolescencia la juventud-, ese cúmulo de horas, de días, de meses y de años, se yergue frente a él y le anonada con su peso terrible» (Azorín 1976c: 30); y, en Un pueblecito, Riofrio de Ávila se exclama: «iOh dolor del tiempo que pasa!» (Azorín, 1976b: 150). 
perder el sentido de la realidad y el de la propia persona ${ }^{103}$. Los tres muestran hasta qué punto «el mal» puede trastocar la vida de un sujeto llegando a cambiarle la personalidad, «y así aparecen neuróticos y psicóticos, con su comportamiento específico», en las novelas azorinianas (Manso, 1993: 179).

El personaje de Capricho vive encerrado por sus crisis de angustia ${ }^{104}$; en Doña Inés, Pablo de Silva se entrega a su quehacer si se lo permiten sus fobias y obsesiones de enfermo; igual que Víctor Albert lo hace atemorizado por varias enfermedades ${ }^{105}$, sobre todo, «la neurastenia, auténtico y único mal que padece nuestro personaje». No extraña, pues, que su médico le diga: «Tu no eres enfermo, Víctor, sino un candidato a enfermo» (Azorín, 2006: 153) ${ }^{106}$. En resumen, esta novela «constituye un documento autobiográfico de excepcional importancia» (Granjel, 1958: 169), ante el cual la crítica literaria no duda en concluir: «Víctor Albert, el más importante enfermo azoriniano, es fiel trasunto literario de su creador; pero no sólo él, todos los personajes sin salud son una reencarnación libresca de una faceta de la humana personalidad de quien les dio vida» (Granjel, 1960: 326). De ahí el interés de nuestro novelista por estudiar el psiquismo del paciente - el suyo - en obras de ficción, desde la juventud a la madurez ${ }^{107}$ y de esta enfermedad — calificada por Granjel de

${ }^{103}$ En todos, se muestra cómo influye la enfermedad en la idiosincrasia de quien la padece. Así, en Los pueblos, el autor asegura: «no llegaréis a sentir la completa e inexpresable efusión con la energía universal [...] acaso al salir de una larga e incierta enfermedad que os ha mostrado abierto ante vuestras miradas el eterno vacío...» (Azorín, 1943a: 362). El subrayado es nuestro.

104 «He leído alguno de vuestros libros de medicina. Sí, ya recuerdo: topofobia. Pues tengo topofobia aguda. No puedo salir a la calle y divagar por la ciudad; tengo la sensación de una ansiedad que no puedo reprimir, de un malestar que no alivio con nada. Con nada más que acurrucándome en este cuarto, en el fondo de este caserón» (Azorín, 1943b: 136).

105 «Tres enfermedades, las tres graves, creyó Víctor Albert padecer o tener predisposición para sufrirlas: el mal de Bright, la nefritis crónica, la dolencia que describió Beard como neurastenia y la enfermedad de Friedrich, la ataxia, que menciona como pavoroso "morbo"; a cada una consagra Azorín un capítulo en su obra [El enfermo]. Otros padecimientos de los que sólo hace el protagonista fugaz referencia son la tabes dorsal y los síntomas de Stokes-Adams, Little y Pavy» (Díaz de Revenga, en Azorín, 2006: 19). Su médico asegura, aunque «...tienes el presentimiento de acabar atáxico; no veo en ti síntomas premonitorios del mal» (Azorín, 2006: 159-160).

106 Menos relieve tienen como enfermos Pascual Verdú, tío de Azorín en La voluntad, recluido en Petrel, donde se refugia con sus males; o el novelista Eladio Peña, en el relato Voluptuosidad, marcado por sus cambios de carácter y visión del mundo a partir de un estado febril; o el protagonista de Lo fatal, en Castilla: «Ni los más experimentados físicos aciertan a decidir lo que el hidalgo tiene. Muchos le han visitado; por estas salas han desfilado graves doctores. [...] Multitud de mixturas, jarabes lenitivos, aceites y pistajes han entrado en su cuerpo o han embadurnado sus miembros. Nada ha contrastado el misterioso mal» (Azorín, 1943a: 536).

107 En El enfermo se lee:

«-¿Qué está usted haciendo ahora? 
«neurosis»y por Merenciano, de «psicosis mitis» ${ }^{108}$ (Granjel, 1960: 326) dando la clave para interpretar sus creaciones.

Empeñado en ser médico de sí mismo, Martínez Ruiz se pregunta por boca de su ente de ficción ¿qué puede devolver al hombre la salud perdida? Y el Dr. García de Rodas le responde: «Todo hombre inteligente se impone un plan» (Azorín, 2006: 117); es decir, una norma reguladora del quehacer cotidiano, a cuyos dictados sujetarse completamente: «ve lo que le conviene en alimentos, en sueño, en bebidas, en el caminar, en el estar quedo, en las costumbres todas» (Azorín, 2006: 117); principiando por la parquedad en la comida109; horas de trabajo $^{110}$ y otros factores de riesgo como abusar del alcohol o el cambio de estaciones: " ...evitamos, sobre todo, la bebida espirituosa; escrupulizamos sobre el momento de comer y sobre la mayor o menor cocción de los alimentos. No quiero deciros nada del traje en invierno y en la estación estiva, el tiento en la mudanza de veste con el cambio de estaciones». El miedo extraordinario a las corrientes de aire mueve al personaje a encargarse «un anemómetro y un anemóscopo; el anemómetro sirve para conocer la velocidad del viento y el anemóscopo la dirección», todo lo cual le permite pautar su vida «como la de un cartujo o un trapense», lo mismo que su creador: "A mi modo, yo soy también un cisterciense reformado, es decir, un monje trapense» (Azorín, 2006: 172).

Igual que reconocemos lo dicho por Martínez Ruiz sobre su plan vital en El enfermo, también los consejos sobre la dieta. Si, en Lecturas españolas, se recomienda la sencillez — «Mi mesa es sobria. No me gustan las cosas complicadas. Como principalmente vegetales y frutas. Me place conservar, después de levantarme de la mesa, la sensación de no haber comido nada. Para mí sería algo muy penoso tener que tomarme una cucharada de bicarbonato» (Azorín, 1962b: 143) — - en Superrealismo, el novelista aconseja la lentitud al ingerir los alimentos: «Comer lentamente, muy lentamente, masticando con perseverancia; así hacen los labradores del campo monovero. Y ellos, sin haberla aprendido, poseen la difícil ciencia de comer» (Azorín, 1943a: 854). La misma filosofía espartana defiende su alter ego literario, Víctor Albert: «Almuerza sobriamente $[. .$.$] Importa que el yantar diario, el yantar meridiano, sea frugalísimo [...]$

- Una novela; cosa ligera; la novela de un enfermo.

- Será curiosa, la psicología de un enfermo es una psicología especial. Hay que analizar anímicamente a un enfermo de distinto modo que a un sano» (Azorín, 2006: 122-123).

108 El psiquiatra Marco Merenciano diagnostica la patología de Pablo de Silva como «un proceso psicótico mitigado», «un estilo doloroso de vivir»; porque «es un psicópata, [que] vive su existencia en la frontera, nunca muy precisa, que deslinda el estado de salud del que llamamos enfermedad» (en Granjel, 1960: 329).

109 «...miro y remiro mucho cuanto como y en qué cantidad lo como [...] te excedes en tu frugalidad $[\ldots]$ esa tenuidad en mi alimentación es un resultado de mi experiencia, una experiencia de muchos años» (Azorín, 2006: 118, 133 y134).

110 «[trabajo] desde las dos hasta las ocho de la mañana» (Azorín, 2006: 118-119). 
a la frugalidad se ha de añadir la sencillez, dentro de la limpieza, en loza y cristales», pues «No puede darse trabajo fluido con el hartazgo. No puede compaginar el escribir bien y el repapilarse» (Azorín, 2006: 85 y 135-136) o el protagonista de El escritor, que ingiere: «Lo que necesito para vivir: muy poco; casi menos que un cartujo» (Azorín, 1957a: 44).

La sobriedad en el comer es consecuencia de aplicar como norma de vida la observación propia: «esa tenuidad en mi alimentación es un resultado de mi experiencia, una experiencia de muchos años. Todos debemos estudiarnos y todos debemos poseer, como resultado de nuestro estudio, un canon de vida y una terapéutica» (Azorín, 2006: 134). Los de Víctor Albert son dominar o ser dominado. Si elegimos bien, ello nos convierte en «dueños absolutos del alimento, animal o vegetal, que tenemos en la mesa» pues, «desde el momento en que lo ingerimos, el alimento es dueño absoluto de nosotros»; de ahí que el personaje coma «lo que he experimentado que me conviene y en la cantidad que me conviene ${ }^{111}$. No cedo nunca, en una mesa fastuosa, a la tentación» (Azorín, 2006: 134).

Estas afirmaciones nos recuerdan las defendidas anteriormente por el autor al preconizar el estudio de sí mismo y la observación como base de la terapéutica de cada hombre. De ahí que el protagonista de El enfermo reconozca:

— ¿Se ha estudiado usted, Albert? — contesta el Doctor- - [...] cada hombre es un mundo: un mundo con sus leyes propias. [...] ¿Ha leído usted a Cornaro? ${ }^{112}$ - Naturalmente, querido Doctor, que he leído a Luis Cornaro [...]

- $\mathrm{Al}$ fin tiene usted razón. Atengámonos, si podemos, a nuestra experiencia personal (Azorín, 2006: 188-189).

Si Martínez Ruiz habla de los efectos de la edad y del paso del tiempo sobre su actividad de escritor - agudizando el pensamiento y fortaleciendo su yo interno-, lo mismo sucede con sus personajes, que también valoran cómo inciden los años en la faceta creativa, caso de El escritor:

¿Cree usted - me pregunta - que la vejez resta fuerzas al escritor? Cuando todo se apoca en lo viejo, ¿cree usted que permanecen intactas las fuerzas mentales? ¿Qué opina usted de todo esto?» En realidad, opinar, yo no opino nada; lo que

111 «...verdura cocida, apenas aliñada con aceite y sal, y las legumbres, y las frutas» (Azorín, 2006: 135).

112 Luigi Cornaro (1467-1566) fue un veneciano noble que escribió tratados sobre la dieta como Discorsi della Vita Sobria (Discursos sobre la vida sobria). Viendo cerca la muerte a los 35 años modificó sus hábitos alimenticios, restringiendo la ingesta calórica, y murió a los 98 años. Su primer tratado lo redacta a los 83 años, El seguro y cierto método para alcanzar una larga y saludable vida (Padua, 1558). Explica Azorín: «Cornaro se impuso una regla inflexible; de laminero refinado y copioso pasó a ser casi un anacoreta. Su nuevo sistema le salvó: desaparecieron todos sus achaques; vivió sano y alegre» (Azorín, 1966: 33). 
hago es sentir. Indudablemente, siento la vida y veo las cosas de distinta manera que en la mocedad. No escribo lo mismo. No tengo ahora, esta es la verdad, ni la fluidez, ni el color, ni el ímpetu de los verdes años (Azorín, 1957a: 89).

Pese a todos los inconvenientes de la enfermedad, el alicantino acaba preguntándose si la vida del artista hipocondríaco — que «se queja de muchas cosas imaginarias» (Azorín, 2006: 104) — no es más intensa y receptiva de los matices y, en consecuencia, superior a la del hombre sano: «Vivía el presente Albert como no había vivido nunca; percibía ahora matices de las cosas que nunca había percibido [...] Y si ahora, enfermo, recogía matices y cambiantes de las cosas que antes no recogía, ¿era esto tenuidad o densidad? ¿Vivían los demás la vida densa, estando sanos, o la vivía él?» (Azorín, 2006: 167). La respuesta apunta a la mayor capacidad de percibir sensaciones y matices durante la enfermedad que, sin ella, se perdían, en un estado de acusada «cenestesia» ${ }^{113}$.

Podemos concluir asegurando que Azorín ficcionaliza en sus obras la propia experiencia de la enfermedad y, en este sentido, es interesante porque ello nos permite conocer su visión de la vida, condicionada por un estado depresivo. Lector voraz de literatura médica, reconocemos a Martínez Ruiz en su ente de ficción, cuando confiesa leer con asiduidad la Farmacopea matritense de 1823114: «estoy todos los días enfrascado en libros de patología» (Azorín, 2006: 123) y mostrarse «curioso de cuantos medios de curación existen» (Granjel, 1960: 326):

El libro que ahora lee Víctor es la Farmacopea matritense, impresa en 1823 [...] le gusta ver cómo la farmacopea ha ido cambiando desde el s. XVII, por ejemplo, hasta nuestros días. El s. XVIII atrae a Víctor singularmente; en ese siglo se dan los grandes observadores. Nada más curioso que ir repasando los autores que en esa centuria representaban, en medicina, la autoridad máxima. La erudición en los tratados de patología ha cambiado totalmente (Azorín, 2006: 125).

Sus libros, sin embargo, también evidencian que la literatura se puede vivir como una enfermedad: no al modo de Don Quijote o Madame Bovary, víctimas de un exceso de lecturas; sino en la línea que Enrique Vila-Matas traza en su novela El mal de Montano (2002), convirtiendo la incapacidad de escribir en un mal y en su principal tema literario. De este modo y adelantándose muchos

113 cenestesia 'sensación general de la existencia y del estado del propio cuerpo' (DRAE): «al dolor sucedió cierta languidez que no carecía de dulzura. [...] En tal grado de cenestesia $[\ldots]$ percibía ahora matices de las cosas que nunca había percibido. Como no podía entregarse a las grandes sensaciones, gustaba de las tenues, que antes pasaban para él inadvertidas. [...] ahora, enfermo, recogía matices y cambiantes de las cosas que antes no recogía» (Azorín, 2006: 167).

114 Al personaje de El enfermo, «Le atrae el nepentes; el nepentes (láudano opiado) - lo ha leído en la Farmacopea matritense, en castellano, de 1823— (Merenciano, 1947: 180). 
años a Roberto Bolaño, Martínez Ruiz verá en la literatura un modo de sufrimiento (lucha por expresarse, períodos de sequedad, falta de reconocimiento... ${ }^{115}$ ). Pese a todo, la escritura se propone como fármaco capaz de salvar a nuestro autor, ayudándole a mantener cierta estabilidad frente a la depresión; o darle consuelo y alivio con las palabras, que actúan como arma y escudo para conjurar el dolor, a la vez que como poderosa forma de conocimiento.

\section{BIBLIOGRAFÍA CITADA}

Aldecoa, Josefina (2001). Con otra mirada: una visión de la enfermedad desde la literatura y el Humanismo. Madrid: Fundación de Ciencias de la Salud / Residencia de Estudiantes / Taurus.

Alfonso, José (1958). Azorín. En torno a su vida y a su obra. Barcelona: Aedos.

Arana, José Ignacio de (1995). Historias curiosas de la medicina. Madrid: Espasa-Calpe.

Azorín [Martínez Ruiz, José] (1919). «El político», en Azorín, Obras completas, VIII. Madrid: Caro Raggio.

Azorín [Martínez Ruiz, José] (1924). Racine y Molière. Madrid: Impr. Ciudad Lineal.

Azorín [Martínez Ruiz, José] (1929). Veraneo sentimental. Zaragoza: Librería General. Imprenta Sáez. Publicado por primera vez en el diario España, 11/7/1904 a 15/8/1904.

Azorín [Martínez Ruiz, José] (1940). Don Juan. Madrid: Espasa-Calpe.

Azorín [Martínez Ruiz, José] (1941). Tomás Rueda. Madrid: Espasa-Calpe.

Azorín [Martínez Ruiz, José] (1942). «La vida», $A B C .5$ de junio.

Azorín [Martínez Ruiz, José] (1943a). Obras selectas. Madrid: Biblioteca Nueva.

Azorín [Martínez Ruiz, José] (1943b). Capricho. Madrid: Espasa-Calpe.

Azorín [Martínez Ruiz, José] (1944). Salvadora de Olbena. Zaragoza: Cronos.

Azorín [Martínez Ruiz, José] (1946). El artista y El estilo. Madrid: Biblioteca Nueva.

Azorín [Martínez Ruiz, José] (1948). Obras Completas, VIII. Madrid: Aguilar.

Azorín [Martínez Ruiz, José] (1957a). El escritor. Madrid: Austral.

Azorín [Martínez Ruiz, José] (1957b). Pueblo (Novela de los que trabajan y sufren). Madrid: Espasa-Calpe.

Azorín [Martínez Ruiz, José] (1959a). Obras completas, I. Madrid: Aguilar.

Azorín [Martínez Ruiz, José] (1959b). Andando y pensando. Buenos Aires: Espasa-Calpe.

Azorín [Martínez Ruiz, José] (1960). Ejercicios de castellano (España, 1873-1967). Madrid:

Biblioteca Nueva.

Azorín [Martínez Ruiz, José] (1962a). Historia y vida. Madrid: Espasa-Calpe.

Azorín [Martínez Ruiz, José] (1962b). Lecturas españolas. Madrid: Espasa-Calpe.

Azorín [Martínez Ruiz, José] (1963). María Fontán. Barcelona: Vergara.

Azorín [Martínez Ruiz, José] (1966). Los médicos. Valencia: Prometeo.

Azorín [Martínez Ruiz, José] (1976a). «La medicina», Las terceras de ABC. Madrid: Prensa Española, pp. 68-71.

Azorín [Martínez Ruiz, José] (1976b). Un pueblecito: Riofrío de Ávila. Madrid: Espasa-Calpe. Azorín [Martínez Ruiz, José] (1976c). Blanco en azul: cuentos. Madrid: Espasa-Calpe.

115 «[el poeta] no quiere verse en el trance de hablarnos de su achaque. No lo habrá más agudo que no poder ya escribir» (Azorín, 1943b: 112). 
Azorín [Martínez Ruiz, José] (1992). Artículos anarquistas. J. M. ${ }^{a}$ Valverde (ed.). Madrid: Lumen.

Azorín [Martínez Ruiz, José] (1995). Cinematógrafo: artículos sobre cine y guiones de películas (1921-1964).Valencia: Pre-Textos.

Azorín [Martínez Ruiz, José] (2000). El cine y el momento. Madrid: Biblioteca Nueva.

Azorín [Martínez Ruiz, José] (2006). El enfermo. F. J. Díez de Revenga (ed.). Madrid: Biblioteca Nueva.

Baroja, Pío (1896). El dolor. Estudio de psicofísica. Madrid: Imprenta de Diego Pacheco Latorre, Plaza del Dos de mayo 5. También en Hojas sueltas. Madrid: Caro Raggio, 1973, pp. 355-410.

Cortejoso, Leopoldo (1943). El dolor en la vida y en el arte. Ensayos medicobiográficos sobre tuberculosos célebres. Barcelona: Iberia-Joaquín Gil editor.

Cortejoso, Leopoldo (1955). El poeta y su secreto. Psicopatología de la lírica romántica. Madrid / Valladolid: Server / Cuesta.

Cortejoso, Leopoldo (1956). Tuberculosos célebres: grandes personalidades forjadas por la tuberculosis. Madrid: Mateu.

Cortejoso, Leopoldo (1969). Los otros (Biografía lírica de una enfermedad). Pedro Laín Entralgo (pról.). Madrid: Graficas Orión.

Daudet, Alphonse (2003). En la tierra del dolor. J. Barnes (ed.). Barcelona: Alba.

Díaz-Plaja, Guillermo (1967). Azorín y los libros. Madrid: Instituto Nacional del Libro.

Escartín, Montserrat (2014). «Literatura y medicina: genio y locura», Ínsula. 813, septiembre, pp. 2-7.

Escohotado, Antonio (2001). Historia general de las drogas. Madrid: Espasa-Calpe.

Fernández Martínez, M. ${ }^{a}$ Pilar (2000). «El dolor en Pío Baroja; análisis de una tesis», en Florencio Sevilla y Carlos Alvar (ed.), Actas XIII: Congreso de la Asociación Internacional de Hispanistas II (6-11 de julio de 1988). Madrid: Castalia, pp. 170-176.

Font Quer, Pío (1980). Plantas medicinales, el Dioscórides renovado. Barcelona: Labor.

Gimeno Cabañas, Amalio (1956). La lucha contra la vejez. Discurso del académico electo Excmo. Sr. Dr. D. Amalio Gimeno Cabañas leído en el acto de su recepción como numerario el día 3 de julio de 1910; Segunda ed. Madrid: J. Cosano.

Granjel, Luis S. (1958). Retrato de Azorín. Madrid: Guadarrama.

Granjel, Luis S. (1960). «Médicos y enfermos en las obras de Azorín», en Baroja y otras figuras del 98. Madrid: Guadarrama, 1960, pp. 315-336.

Granjel, Luis S. (1998). «Lectura médica de El enfermo de Azorín», en Carmen Rico Navarro (coord.), Azorín y Petrer. Petrer: Ajuntament de Petrer / Caixa de Crèdit de Petrer / Universitat d'Alacant, pp. 165-172.

Haining, Peter (1975). Hashish Club: Antology of Drug Literature. London: Editorial Peter Owen.

Jamison, Kay R. (1998). Marcados con fuego: la enfermedad maniaco-depresiva y el temperamento artístico. México: FCE.

Kierkegaard, Sorien (1993). Diario intimo. J.L. Aranguren (pról.); M. a Ángeles Bosco (trad.). Barcelona: Planeta.

Mandado Gutiérrez, Ramón Emilio (2007). «La tesis doctoral de Pío Baroja: de la medicina a la literatura filosófica», Boletín del Ilustre Colegio Oficial de Doctores y Licenciados en Filosofia y Letras y en Ciencias. 183, marzo, pp. 23-25.

Manso, Christian (1993). «Un español en París: dolor y melancolía», Actes du premier Colloque International José Martínez Ruiz. Pau: Université de Pau, pp. 171-188.

Martínez Ruiz, José [«Azorín»] (2000). Diario de un enfermo. Francisco José Martín (ed.). Madrid: Biblioteca Nueva. 
Martínez Ruiz, José [«Azorín»] (2015). Diario de un enfermo. M. Escartín (ed.). Madrid: Cátedra.

Merenciano, Francisco Marco (1947). Fronteras de la locura. Tres personajes de Azorín vistos por un psiquiatra. Valencia: Metis. Imp. J. Doménech.

Montaigne, Michel de (2005). Ensayos completos. Madrid: Cátedra.

Ortega y Gasset, José (1954). «Azorín, primores de lo vulgar», en Azorín, Obras completas, II. Confesiones de El espectador (1916-1934). Madrid: Revista de Occidente, pp. 157191.

DRAE = Real Academia Española (2014). Diccionario de la Lengua Española. 23. ${ }^{a}$ ed. Madrid: Espasa-Libros.

Rico Verdú, José (1973). Un Azorín desconocido (Estudio psicológico de su obra). Alicante: Diputación Provincial de Alicante / Instituto de Estudios Alicantinos.

Ruiz de la Cuesta, Francisco (1974). «Radiografía espiritual y humana de José Martínez Ruiz (Notas sobre la medicina y los médicos en Azorín)», en Azorín 100 años. Sevilla: Secretariado de Publicaciones de la Universidad de Sevilla, pp. 43-60.

Sánchez Martín, Antonio (1997). Ideología, politica y literatura en el primer Azorín (18931905). Madrid: Endymion.

Selva Roca de Togores, Enrique (2012). «El giro antirromántico de Azorín y La reinvención de Larra», en Azorín, Los clásicos redivivos y los universales renovados. Pascale Peyraga (ed.). Alicante: Instituto de Cultura Gil-Albert, pp. 233-249.

Sendrail, Marcel (1983). Historia cultural de la enfermedad. Madrid: Espasa-Calpe.

Sontang, Susan (1996). La enfermedad y sus metáforas. El sida y sus metáforas. Madrid: Taurus.

Stary, Frantisek (1990). Plantas venenosas. Barcelona: Omega.

Unamuno, Miguel de (2006). Abel Sánchez, San Manuel Bueno mártir, Cómo se hace una novela y otras prosas. Domingo Ródenas (ed.). Barcelona: Crítica.

Unamuno, Miguel y Joan Maragall (1951). Epistolario y escritos complementarios. Barcelona: Editar.

Vaz de Soto, José M. ${ }^{\text {a }}$ (1974). «Azorín y Baroja», en Azorín 100 años. Sevilla: Secretariado de Publicaciones de la Universidad de Sevilla, pp. 153-172.

Vega-Díaz, Francisco (1987). «Fallas prosódicas en Azorín y Valle-Inclán», Cuadernos Hispanoamericanos. 448, pp. 105-111.

Vidal, José Manuel (2007). «El enfermo, de Azorín», Monteagudo. 12, pp. 229-232.

Vila-Matas, Enrique (2002). El mal de Montano. Barcelona: Anagrama.

Fecha de recepción: 27 de octubre de 2014

Fecha de aceptación: 12 de marzo de 2015. 